\title{
Características Socioeconômica e ambiental da Agricultura Urbana em Imperatriz-MA
}

\author{
Edson Aparecida Araujo Querido Oliveira \\ Universidade de Taubaté - Taubaté - São Paulo - Brasil \\ Luciana Learte Moura Nunes \\ Universidade de Taubaté e Instituto Federal do Maranhão - Taubaté - São Paulo \\ - Brasil
}

Marcela Barbosa de Moraes

Universidade de Taubaté - Taubaté - São Paulo - Brasil

\begin{abstract}
Resumo
A pesquisa tem como objetivo diagnosticar a agricultura urbana no município de Imperatriz do maranhão, assim como suas características sócio produtiva. A investigação se fez a partir da coleta de dados em uma abordagem qualitativa de caráter descritivo, com estudo de campo. Os dados foram coletados em entrevistas semiestruturada da qual participaram 36 agricultores urbanos, residentes em três bairros do município de Imperatriz (MA). Para o procedimento de análise de dados foram utilizadas técnicas qualitativas de sensemaking. Por fim, os resultados evidenciaram que agricultura urbana se apresentou como uma atividade com grande potencial de melhoria de qualidade de vida dos entrevistados envolvidos. Diante dos dados obtidos evidencia-se a atuação da agricultura urbana, assim como a contribuição socioeconômica e ambiental proporcionada aos agricultores urbanos e à comunidade do município de Imperatriz (MA).
\end{abstract}

Palavras-chave: Gestão. Desenvolvimento Regional. Agricultura Urbana.

Socioeconomic and Environmental Characteristics of Urban Agriculture in Imperatriz-MA

\begin{abstract}
The research aims to diagnose urban agriculture in the municipality of Imperatriz Maranhão, as well as its socio-productive characteristics. The investigation was based on data collection in a qualitative descriptive approach, with field study. Data were collected in semi-structured interviews involving 36 urban farmers living in three neighborhoods of Imperatriz (MA). For the data analysis procedure qualitative sensemaking techniques were used. Finally, the results showed that urban agriculture presented itself as an activity with great potential to improve the quality of life of the interviewees involved. Given the data obtained, it is evident the performance of urban agriculture, as well as the socioeconomic and environmental contribution provided to urban farmers and the community of Imperatriz (MA).
\end{abstract}

Keywords: Management. Regional Development. Urban Agriculture. 


\section{Características Socioeconómicas y Ambientales de la Agricultura Urbana em Imperatriz-} MA

\section{Resumen}

La investigación tiene como objetivo diagnosticar la agricultura urbana en el municipio de Imperatriz - Maranhão, así como sus características socio productivas. La investigación se basó en la recopilación de datos en un enfoque descriptivo cualitativo, con estudio de campo. Los datos se recopilaron en entrevistas semiestructuradas con 36 agricultores urbanos que viven en tres barrios de Imperatriz (MA). Para el procedimiento de análisis de datos se utilizaron técnicas cualitativas de creación de sentido. Finalmente, los resultados mostraron que la agricultura urbana se presentaba como una actividad con gran potencial para mejorar la calidad de vida de los entrevistados involucrados. Dada la información obtenida, es evidente el desempeño de la agricultura urbana, así como la contribución socioeconómica y ambiental brindada a los agricultores urbanos y la comunidad de Imperatriz (MA).

Palabras clave: Gestión. Desarrollo Regional. Agricultura Urbana.

\section{Introdução}

A produção agrícola urbana no Brasil, entre os anos de 1940 e 1970, estava distante das políticas públicas, o que levava tal ramo de atividade a não ter apoio de grandes instituições políticas e econômicas. Era uma atividade executada quase que exclusivamente pela população migrante da zona rural, resultando na exclusão desse setor na formalização de empregos (NOLASCO, 2009).

Em 1980, com o Programa das Nações Unidas para os Assentamentos Humanos (UN-HABITAT), iniciaram-se no Brasil vários debates direcionados ao conceito de agricultura urbana, mas somente na década de 1990 esses debates começaram a obter repercussão com a inclusão da temática na agenda de Segurança Alimentar e Nutricional (SAN). A partir dessa inclusão surgiram várias conceituações, caracterizando a temática agricultura urbana por diferentes órgãos e autores (ARRUDA, 2006).

Para a Organização das Nações Unidas para Alimentação e Agricultura - FAO (2000), a agricultura urbana pode ser executada dentro e nos arredores das cidades, podendo cultivar plantas, criar animais e produzir alimentos de consumo imediato, como hortaliças, leite, ovos, frangos e peixes, além da plantação de ervas medicinais e aromáticas, mudas de árvores, plantas ornamentais e flores.

Mougeot (2005) também relata que existem diferentes definições de agricultura urbana. Essas definições incluem itens como localização, tipos de área onde é praticada, classificação dos produtos, destino da produção e tipos de atividades econômicas que podem proporcionar à população envolvida.

Para Mougeot (2005):

a agricultura urbana é a praticada dentro (intraurbana) ou na periferia (periurbana) dos centros urbanos (sejam eles pequenas localidades, cidades ou até megalópoles), onde cultiva, produz, cria, processa e distribui uma variedade de produtos alimentícios e não alimentícios, utiliza largamente os recursos humanos e materiais e os produtos e serviços encontrados dentro e em torno da área urbana, e, por sua vez, 
oferece recursos humanos e materiais, produtos e serviços para essa mesma área urbana (MOUGEOT, 2005, p. 7).

Essa definição coaduna com a da FAO (1999), pelo fato de a agricultura urbana ser uma prática executada em áreas pequenas, seja ela dentro da cidade ou em seu entorno, de forma que a produção é destinada ao consumo próprio ou à venda em pequena escala, em mercados locais.

As práticas agrícolas requerem mão de obra para um trabalho intensivo e auxiliam o combate à miséria, mesmo em pequena escala. Melhoram a segurança alimentar e nutricional das comunidades urbanas e estabelecem um habitat urbano melhor.

Segundo Boukharaeva et al. (2005), a atuação da agricultura urbana e periurbana é vista como uma forma direcionada a diminuir inúmeras situações provocadas para a exclusão de determinada população que vive em áreas urbanas de países com um grande índice de desigualdade social e econômica. É uma opção que atende às necessidades dessa população, proporcionando oportunidades de emprego que melhoram os índices de renda e atendem suas necessidades alimentares.

Nas últimas décadas, o crescimento das populações urbanas tem superado significativamente o das populações rurais. Por esse fator, surgem na sociedade novas demandas que trouxeram à tona a agricultura urbana não somente como uma forma de renda e geração de emprego, mas também como uma forma de lazer, terapia, recreação e, às vezes, produção agrícola de subsistência (NOLASCO, 2009).

É necessário abranger o papel da agricultura urbana, que tem uma diversidade de práticas atuantes e que envolve diversos grupos de famílias com o objetivo de gerar emprego e renda. É base de produções sustentáveis, proteção ambiental e atua com base na segurança alimentar, alcançando as necessidades da população que a prática (IFPRI 1998; SMIT, 1994).

Para Nugent e Egal (2000), a agricultura urbana distingue-se por atuar no setor socioeconômico com práticas agrícolas distintas. É formada pela produção hortícola para o abastecimento do mercado, definição dada para a indústria hortícola e graneleira, direcionada à produção de subsistência das unidades domésticas pobres presentes nas áreas urbanas e periurbanas, onde a existência de terra e a pobreza criam a oportunidade e a necessidade.

Essa agricultura de subsistência no meio urbano, na maioria, é realizada em quintais, mas também em áreas de órgãos públicos ou propriedades privadas que são ocupadas de formas diversas (MENDONÇA; MONTEIRO, 2004).

Diante do exposto, observou-se a importância do debate referente ao desenvolvimento local com respeito à geração de emprego, renda, melhoria nutricional e ambiental, visto que no município de Imperatriz do Maranhão ainda não constam diagnósticos e caracterização econômica, social e ambiental da produção agricultura urbana. Para levantar essas informações é que o presente estudo busca responder às seguintes questões: quais são as características da agricultura urbana quanto aos aspectos socioeconômico e ambiental no município de Imperatriz (MA)? 


\section{Agricultura Urbana: conceitos, características e dimensões}

Apesar de existir várias conceituações e utilização da definição de agricultura urbana por ONGs, órgãos internacionais, como o Programa das Nações Unidas para o Desenvolvimento (PNUD) e FAO, essas definições advêm de vários questionamentos sobre o que há de autenticidade na agricultura urbana para que ela seja identificada como um instrumento de políticas específicas e investigação em pesquisas de caráter científico.

Nas definições e trabalhos científicos encontram-se algumas características como: o tipo de atividade que está direcionada aos fatores econômicos; as categorias dos insumos utilizados; características do local de implantação (intra e periurbana); e tipos de áreas e processos de destinação da produção (AQUINO; MONTEIRO, 2005).

Dentro dessa contextualização, a FAO (2000) destaca ainda que essa abrangência da agricultura urbana se deve à expansão das cidades, onde crescem as necessidades das famílias urbanas, e relata as diferenças entre os aspectos que diferem a agricultura urbana da rural, destacando entre os fatores o ambiente, pois a agricultura urbana pode ser realizada em qualquer ambiente urbano ou periurbano, podendo ser praticada diretamente no solo, em canteiros suspensos, em vasos, ou onde a criatividade sugerir.

A maior abrangência da agricultura urbana quanto à produção de alimentos dentro das cidades pode se dar em espaços abertos, públicos ou privados, com o aumento da utilização das terras urbanas, evitando a escassez de alimentos aos produtores e à população em decorrência das flutuações salariais e limitações econômicas.

Esses benefícios, alcançados com a prática da agricultura urbana, fazem com que aumentem as chances de acesso a alimentos essenciais na dieta diária e criação de uma alternativa de renda e emprego para a população (AQUINO; MONTEIRO, 2005).

Mougeot (2000), Aquino e Monteiro (2005) demonstram as características da agricultura urbana com suas particularidades, características e dimensões, que podem diferenciá-la e destacá-la com base na realidade atribuída a cada grupo que convive com as experiências que a envolvem.

Figura 1 - Características da agricultura urbana

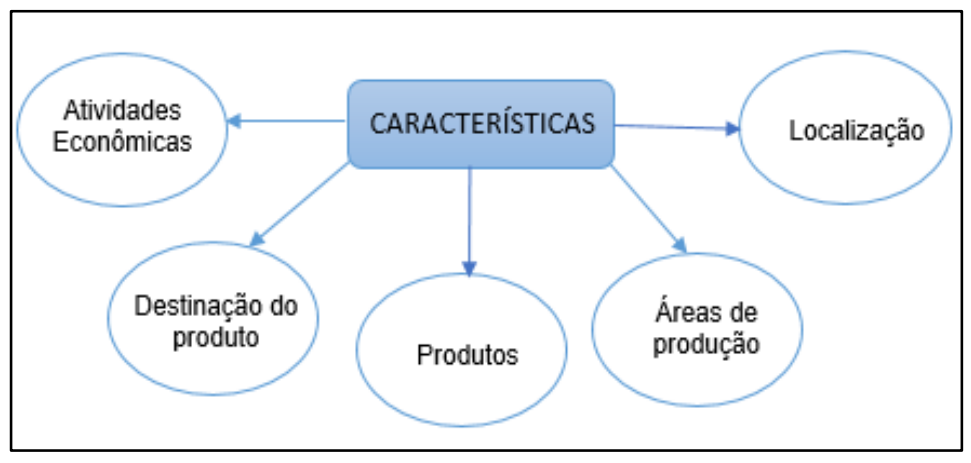

Fonte: Mougeot (2000, p. 18) 
Conforme explicam Aquino e Monteiro (2005), o processamento ligado aos agricultores urbanos está diretamente ligado a vários setores, utilizado de forma diversa para atender à subsistência e comercialização com processos caseiros. Podem atingir diferentes áreas por apresentar uma diversidade de atividades englobadas em um mesmo contexto, o que é uma das suas principais características e importância para fins urbanos.

Entre as características podem-se citar alguns exemplos que demonstram, com maior clareza, as limitações de cada característica da agricultura urbana de acordo com Mougeot (2000).

- Atividades econômicas:

- atividade agrícola e atuação na pecuária, produção de peixes; agroextrativismo e insumos;

- elaboração de pelo menos um produto de forma artesanal, que venha transformar a agricultura urbana em uma pequena agroindústria familiar e ou comunitária; e

- preços compatíveis com a realidade do local, com elaboração de produtos in natura ou transformados na cadeia urbana formal ou informal.

- Destinação do produto:

- consumo próprio, vendas, trocas e até mesmo doações que possam beneficiar a comunidade geral ou instituições que necessitam.

- Produtos:

- horticultura: hortaliças, frutas, plantas medicinais e flores;

- criações: animais de pequeno e grande porte e seus derivados;

- aquicultura: peixes, frutos-do-mar e algas marinhas;

- agrofloresta: agrícola, madeiras, sementes, combustível; e

- variedades: flores, plantas ornamentais; plantas exóticas.

- Áreas de produção:

-áreas verdes: parques, praças, canteiros;

-terrenos privados: lajes, baldios, áreas verdes, quintais;

-áreas públicas: escolas, edifícios públicos, creches, posto de saúde;

-áreas gerais: laterais de estradas e avenidas, áreas inundáveis; laterais de vias férreas; e

\section{- Localização:}

- urbano: intraurbana e periurbana;

- terreno: baldios ou área construída;

- $\quad$ residência do agricultor: dentro ou fora da área onde reside; e

- $\quad$ posse da terra: arrendamento, usufruto, acordos, transação.

Machado (2002) também relata e confirma as características citadas por Mougeot (2000), quando destaca na sua definição que a agricultura urbana se localiza dentro e aos redores da cidade.

O autor exemplifica as características intraurbanas, quando define sua localização em todos os espaços dentro da cidade, com ações executadas individualmente ou coletivas, em áreas privadas ou públicas, que possam transformar essas áreas em ambientes produtivos de forma a oferecer melhor qualidade de vida às comunidades locais. 
Segundo a compreensão de Menezes, Burlandy e Maluf (2004), a inclusão da prática da agricultura urbana ativa em uma política faz com que aconteça a otimização de espaços ociosos nos núcleos urbanos e em suas periferias, muitos deles propostos à especulação imobiliária e sujeitos à degradação ambiental.

Esses problemas, conforme ressaltam os autores, podem ser reduzidos com a agricultura urbana e incentivo à implantação de projetos participativos para uma produção ativa e que possibilite o acesso, a baixo custo, a hortaliças, frutas, pequenos animais e ervas medicinais.

Podem ser, também, estímulos agregados à educação alimentar, diversificação e valorização da cultura alimentar local, além de fortalecimento da agricultura de base familiar, servindo como fonte de renda para várias famílias e comunidades.

A agricultura urbana nos últimos anos vem sofrendo grandes transformações conforme as mudanças tecnológicas, ambientais e políticas. Essas mudanças são estimadas de acordo com o crescimento e participação de pessoas envolvidas no mundo inteiro em atividades voltadas à agricultura urbana, em atividades quantificadas e baseadas em projeções, levantamentos, observações e pesquisas atuais.

As mudanças que ocorrem diante das atividades relacionadas à agricultura urbana são expressivas quando se analisa o que Mougeot (2000) relata: que ela sempre esteve presente tanto nas cidades do neolítico quanto nas cidades modernas, apesar de nessa época tanto o poder público quanto os cientistas ignoraram e negligenciaram o seu crescimento.

É possível, então, destacar as dimensões da agricultura urbana, mostrando a sua funcionalidade e importância como evidencia Mougeot (2000), o que demostra ao expor as suas dimensões quanto à utilização, que ela fornece às populações envolvidas não somente benefícios econômicos, mas também ecológicos, diminuição das distâncias entre produtor e consumidor, recreação, lazer, benefícios na qualidade do ar no sistemas urbanos e segurança alimentar (Figura 2).

Figura 2 - Dimensões da agricultura urbana

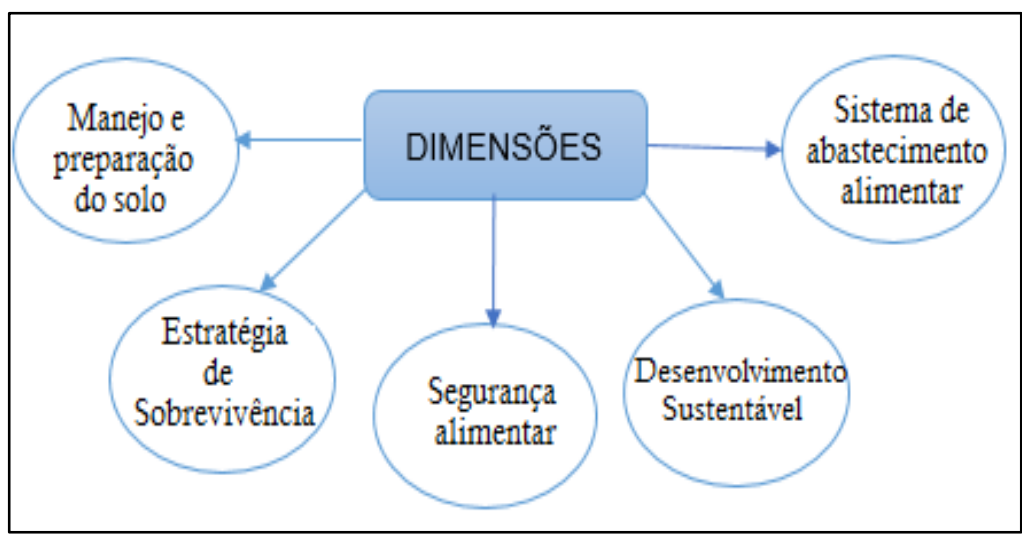

Fonte: Mougeot (2000, p. 25)

A citação de Moldakov (2001), quando expõe que as contribuições e dimensões na agricultura urbana estão direcionadas a uma inclusão de fatores, como acesso a alimentos saudáveis, passatempo e venda pela utilização e uso 
produtivo para melhorar a renda, vem somente demonstrar o quanto a agricultura urbana pode ocupar um espaço importante na qualidade de vida de uma comunidade.

O principal objeto destacado em vários trabalhos, de diversos autores, é que a prática da agricultura urbana está relacionada diretamente à geração de renda pela produção, pois grande parte dos agricultores sobrevivem ou tem a maior parte da renda oriunda da agricultura urbana, mesmo havendo práticas de troca e doações entre as vizinhanças produtoras (MENDONÇA; MONTEIRO, 2004).

A agricultura urbana que acontece no Brasil é bem intensiva e é em grande parte produtora dos alimentos agrícolas utilizados na demanda local, com predominância de ciclos curtos e pequenos circuitos de produção (MACHADO; MACHADO, 2002).

Segundo Boukharaeva et al. (2005), essa atividade é amplamente desenvolvida por famílias pobres, que moram em interior ou nas periferias das cidades, com espaços bastantes reduzidos. Há dificuldade em identificá-las como uma representação tradicional inserida em uma atividade formal ou informal. Os dados relativos a essa atividade ficam sujeitos à verificação e em muitos casos com dificuldade de identificação.

De acordo com Menezes, Burlandy e Maluf (2004), a agricultura urbana aumenta o potencial econômico local e dos locais onde ocorre tal produção, além de contribuir para o abastecimento urbano como instrumento de inclusão social.

É uma forma de aproximar o produtor do consumidor, não havendo gasto com transporte, o que diminui os custos, portanto oferece à população local alimentos de qualidade com menor índice de processamento e uma diversificação dos hábitos alimentares.

Essas exigências estão cada vez maiores por consumidores e produtores em busca de alimentos com qualidade, conquista que pode ser adquirida com parcerias que irão contribuir na construção de uma agricultura urbana com projeto de geração de emprego, renda e acesso aos alimentos.

A multifuncionalidade pela qual se destaca a agricultura urbana vem somente reafirmar o que Soares (2001) destaca quando expõe que a agricultura urbana é identificada por suas funções, que contribuem diretamente à segurança alimentar; função ambiental; função econômica e função social.

A Carta de Brasília (2012) também se refere à multifuncionalidade da agricultura urbana e periurbana, e destaca a sua forte atuação como prática sustentável, limpeza das áreas de produção localizadas no meio urbano, melhoria da imagem da paisagem urbana e dos fatores ligados ao meio ambiente e redução dos impactos da urbanização.

Essa prática, conforme a Carta de Brasília (2012), é característica da dimensão da agricultura urbana, que pode contribuir para aumento das áreas verdes no meio urbano, com base na qualidade de vida da população nos aspectos social, econômico e ecológico.

\section{Procedimentos Metodológicos}


Esta pesquisa quanto ao objetivo é descritiva, pois tem por finalidade investigar as características de determinada realidade ou mesmo descobrir variáveis componentes dessa realidade" (APPOLINÁRIO, 2006, p.115).

O delineamento da pesquisa está baseado em uma pesquisa qualitativa, que permite estudar com maior complexidade um ambiente natural, permitindo contextualizar um possível entendimento dos acontecimentos diários pelas definições e interpretações que as pessoas oferecem ao fenômeno investigado.

A pesquisa foi realizada na cidade de Imperatriz, segundo maior centro populacional do estado do Maranhão, com 247.553 habitantes, área territorial de $1.368,987 \mathrm{~km}^{2}$, apresentando uma densidade de $180,79 \mathrm{hab} / \mathrm{km}^{2}$,

Para a coleta de dados foi aplicada uma entrevista semiestruturada. Optouse por essa técnica por se tratar de uma pesquisa qualitativa. A escolha dos bairros se deu a partir da aceitação da participação nesta pesquisa mediante o contato com líderes dos grupos dos agricultores urbanos.

A pesquisa foi realizada em três bairros/comunidades localizados em áreas periurbanas. São áreas periféricas, localizadas nos bairros Bacuri, Vila Nova e Planalto. Houve a procura por outros bairros, mas a não aceitação dos líderes das comunidades agrícolas impediu o acesso de um maior número de bairros na pesquisa. A amostra envolve, portanto, os agricultores dos três bairros citados.

Com relação ao quantitativo de entrevistados, a população de agricultores nos bairros Bacuri e Planalto são muito semelhantes, com o quantitativo em torno de 13 e 15 agricultores, respectivamente, mas apenas 12 do bairro Bacuri tinham disponibilidade para a entrevista.

O bairro Vila Nova conta com 22 agricultores, contudo foi igualado o número de entrevistado com o bairro Bacuri para não haver disparidade na quantidade de entrevistas quando comparadas. Igualou-se, portanto, a população a 12 entrevistados em cada bairro, totalizando 36 agricultores.

Para o procedimento de análise de dados foram utilizadas técnicas qualitativas de sensemaking, que tem como objetivo dar sentido aos dados. Para criar sentido, a cada entrevista foi utilizada a técnica narrativa por sensemaking, além de utilizar o Excel do pacote Microsoft Office (versão 2010) para encontrar as porcentagens dos referidos resultados.

A técnica narrativa de sensemaking possibilita oferecer voz aos atores envolvidos em uma organização, auxiliando as interpretações diante da realidade dos sujeitos e estruturando aquilo que não é conhecido, portanto dando significado aos sentidos envolvidos (SODERBERG, 2008).

\section{Resultados e Discussões}

Nesta seção expõem-se os resultados e sua discussão a partir dos dados obtidos na pesquisa. O texto está dividido em duas subseções: a primeira traz os aspectos produtivos e suas formas de comercialização e a segunda e última subseção apresenta uma abordagem direcionada à utilização de agroquímicos.

Para preservar a identidade, os agricultores urbanos foram identificados com as letras AUB, referentes a agricultor urbano do bairro Bacuri; AUV, agricultor urbano do bairro Vila Nova; e AUP, agricultor urbano do bairro Planalto. Seguem as letras o número da sequência da entrevista, portanto, cada tabela está identificada 
com resultados de $A U_{1}$ a $A U_{12}$, que se referem aos agricultores urbanos e aos bairros/comunidades.

\subsection{Características Socio-produtivas dos Agricultores}

De acordo com os dados expostos no Quadro 1, dos entrevistados 69\% escolheram a agricultura na cidade como uma forma de dar continuidade à atividade na qual sempre tiveram conhecimento obtido dos pais. Apenas 3\% citou a atividade como uma forma de fugir de problemas de saúde, como a depressão.

Quadro 1 - Opção de trabalho com agricultura na cidade

\begin{tabular}{|l|l|l|l|}
\hline \multirow{4}{*}{$\begin{array}{l}\text { Por que optaram por } \\
\text { trabalhar com agricultura na } \\
\text { cidade? }\end{array}$} & \begin{tabular}{l} 
Bairro Bacuri \\
\cline { 2 - 4 }
\end{tabular} & \multicolumn{1}{|c|}{ Bairro Vila Nova } & \multicolumn{1}{c|}{ Bairro Planalto } \\
\cline { 2 - 4 } & agricultura & $\begin{array}{l}\text { 10-Sempre vivi da } \\
\text { agricultura }\end{array}$ & $\begin{array}{l}\text { 07- Sempre vivi da } \\
\text { agricultura }\end{array}$ \\
\cline { 2 - 4 } & 03-Desemprego & 02-Desemprego & 05-Desemprego \\
\cline { 2 - 4 } & 01- Estresse & - & - \\
\hline
\end{tabular}

Fonte: elaborado pelos autores

Dentre os entrevistados, $28 \%$ optaram por seguir essa profissão como meio de subsistência, em razão do desemprego. Com essa atividade de subsistência alcançam melhores preços graças ao sistema produtivo orgânico escolhido, ao que corrobora Arruda (2011) quando ressalta:

Pensando no impacto social desta agricultura, é possível afirmar que é muito positivo em uma área onde a migração rural e os problemas do desemprego sejam cruciais. Para os agricultores mais vulneráveis economicamente, a existência desta agricultura permite o acesso a alimentos frescos e diversificados e assim conservar os recursos financeiros para a compra de outros produtos (ARRUDA, 2011, p. 143).

Para a realização da fertilização da terra, conforme dados do Quadro 2, a maioria dos agricultores do bairro Bacuri utilizam esterco de gado e frango, com exceção de quatro agricultores que fizeram cursos ou tiveram orientações técnicas e usam, além dos adubos citados, o calcário para auxiliar na nutrição do solo. 0 Quadro 2, a seguir, descreve esses procedimentos.

Quadro 2 - Fertilização do solo

\begin{tabular}{|c|l|l|l|}
\hline \multirow{2}{*}{$\begin{array}{c}\text { Como é feita a } \\
\text { fertilização do solo? }\end{array}$} & \begin{tabular}{l} 
Bairro Bacuri \\
\cline { 2 - 4 } \\
O4- Utiliza calcário e \\
(recebe ajuda de um \\
técnico amigo).
\end{tabular} & $\begin{array}{l}\text { Bairro Vila Nova } \\
\text { 11- Utilizam produtos de } \\
\text { fertilização com } \\
\text { orientação de técnicos do } \\
\text { Sebrae, Senar ou do Eng. } \\
\text { Agrônomo que atua na } \\
\text { área AUV7. }\end{array}$ & $\begin{array}{l}\text { B3- Utiliza calcário e } \\
\text { adubos de gado e } \\
\text { frango. Recebeu } \\
\text { treinamento com } \\
\text { do Sebrae. }\end{array}$ \\
\hline
\end{tabular}




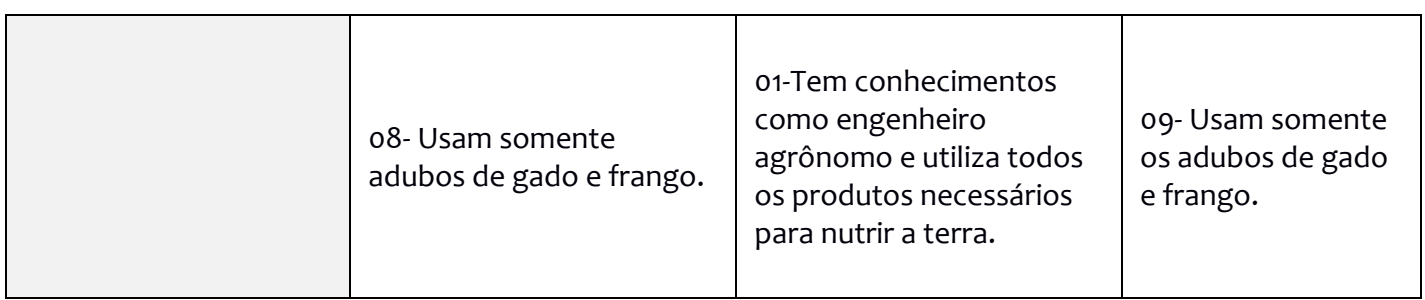

Fonte: elaborado pelos autores

Já os agricultores do bairro Vila Nova, conforme Quadro 2, recebem orientações técnicas e treinamento quanto ao uso de fertilizantes no solo. Alguns, como AUV2, AUV3 e AUV7, constantemente encaminham amostras de solo para 0 laboratório para diagnosticar os fertilizantes necessários.

Os agricultores do bairro Planalto, por sua vez, assemelham-se quanto à forma de adubação aos do bairro Bacuri, embora três deles obtiveram treinamento por meio de empresas, como o Sebrae, e além dos adubos de gado e frango utilizam também o calcário para a nutrição do solo.

Para Mapa (2010), a agricultura urbana no Brasil atualmente estabelece uma diversidade de produtos e técnicas de cultivo correspondentes a cada localidade. Segundo Gonçalves (2014), há na agricultura urbana uma vasta diversificação quanto aos meios de cultivo, criação, técnicas e localização de cada produção. Essa diferenciação destaca-se principalmente em hortas, que são as principais atividades ligadas à agricultura urbana.

Quando se pergunta aos agricultores o tipo de insumos que utilizam na produção agrícola ali existente observa-se, no Quadro 3, que o grupo dos bairros Bacuri e Planalto utilizam insumos tradicionais na agricultura de forma bastante manual. O Quadro 3 mostra essa diversidade de técnicas dos três bairros em estudo.

Quadro 3 - Utilização e formas de adubação

\begin{tabular}{|c|c|c|c|}
\hline \multirow{3}{*}{$\begin{array}{l}\text { Quais os insumos } \\
\text { que são utilizados? }\end{array}$} & Bairro Bacuri & Bairro Vila Nova & Bairro Planalto \\
\hline & $\begin{array}{l}\text { Enxadas } \\
\text { Mangueiras } \\
\text { Facão } \\
\text { Adubos }\end{array}$ & $\begin{array}{l}\text { Tratores - solicitam da } \\
\text { prefeitura, assim como } \\
\text { outros equipamentos } \\
\text { necessários (AUV1 e } \\
\text { AUV3). } \\
\text { Enxadas } \\
\text { Facão } \\
\text { Mangueiras } \\
\text { Adubos } \\
\text { Material para a fertilização } \\
\text { do solo } \\
\text { Estufas }\end{array}$ & $\begin{array}{l}\text { Enxadas } \\
\text { Mangueiras } \\
\text { Facão } \\
\text { Adubos }\end{array}$ \\
\hline & $\begin{array}{l}\text { Sementes: alface, } \\
\text { cebolinha, rúcula, quiabo, } \\
\text { vinagrete, salsa, coentro, } \\
\text { berinjela, couve. }\end{array}$ & $\begin{array}{l}\text { Sementes: Quiabo, } \\
\text { berinjela, alface, } \\
\text { cebolinha, abobrinha, } \\
\text { couve, coentro salsa, } \\
\text { macaxeira, pepino, feijão, } \\
\text { jiló, brócolis, vinagreira, } \\
\text { rúcula. }\end{array}$ & $\begin{array}{l}\text { Sementes: Alface, } \\
\text { cebolinha, rúcula, } \\
\text { vinagrete, salsa, } \\
\text { coentro, couve, } \\
\text { berinjela, abobrinha, } \\
\text { feijão verde e banana. }\end{array}$ \\
\hline
\end{tabular}

Fonte: elaborado pelos autores 
Os agricultores do bairro Vila Nova são orientados pelo Sebrae, Senar e por um engenheiro agrônomo, o AUV7. Produtores como AUV1 e AUV3 ressaltam que quando precisam solicitam à prefeitura tratores e outros equipamentos. São os únicos que relataram o auxílio da prefeitura, citado por ambos como incentivo. Nessa área há também agricultores que utilizam insumos tradicionais, como os dos bairros Bacuri e Planalto.

O produtor AUV4 utiliza, ainda, métodos manuais, porque sua área de produção é muito pequena quando comparada às demais. AUV5 e AUV6 ressaltam que atualmente não se encontram produzindo na área total que arrendaram, assim, não necessitam de grandes insumos para sua produção.

Diferente dos demais agricultores, AUV2 e AUV7 não recebem auxílio de nenhum órgão e quando necessitam de equipamentos fazem a compra dos demais ou alugam. Os demais agricultores têm grande parte dos equipamentos necessários para a produção.

Em relação às sementes utilizadas, é possível observar que o bairro Vila Nova tem maior diversidade de insumos, conforme Quadro 3. Quando se trata da aquisição de sementes, a compra dos agricultores dos bairros Bacuri e Planalto é realizada somente no mercadinho ou feirinhas, não havendo o indicativo de uma empresa específica que oriente a compra.

Já os agricultores do bairro Vila Nova compram em uma das maiores empresas agropecuárias do município para receberem orientação técnica. A exceção é AUV4, que compra aleatoriamente conforme o preço.

No que diz respeito à participação em associações ou cooperativas, 50\% dos entrevistados do bairro Bacuri participam de uma associação ou cooperativa, conforme expressa o Quadro 4.

Quando perguntados a respeito das associações, as respostas apresentadas se direcionaram à facilidade de conseguir participar de programas como o PAA ou facilitar o cadastro para ser beneficiado com algum crédito agrícola.

Esse é outro código indicador da análise, direcionado as mudanças, na qual objetiva a ação, em virtude de haver a definição de um líder para a organização, o que caracteriza a preocupação com ações a fim de reduzir a informalidade e minimizar erros de estratégias.

Esse fator se encontra no bairro Bacuri, quando em algum momento foi identificado um agricultor como líder de associação no grupo, correspondente à comunidade. AUB4 participa de uma associação junto com alguns agricultores que trabalham com ela, mas não tinha uma visão clara do que poderia significar uma associação ou qual contribuição poderia dar.

De acordo com as respostas direcionadas à assistência técnica, abordadas no Quadro 12, 33\% dos entrevistados que buscam essa assistência destacaram o Sebrae como um órgão que auxiliava com algumas informações.

Em relação ao crédito agrícola, somente três agricultores do bairro Bacuri buscaram auxílio no Banco do Nordeste para projetos como o Agroamigo, o Programa de Microcrédito Produtivo Orientado.

A busca de crédito agrícola, apesar de estar na proporção de $25 \%$, demonstra ações para aperfeiçoar a organização. A previsão de manter os alimentos saudáveis e competitivos no mercado faz com que não seja utilizado agroquímico para 
controle de pragas e doenças, identificando assim que o sensemaking está aliado à previsão e guia futuras ações, caracterizando (planos) como código indicador.

Vale ressaltar que os agricultores que confirmaram a busca do crédito agrícola são os mesmos que participam de associações e que citaram as contribuições que elas oferecem, conforme dados do Quadro 4.

Quadro 4 - Características socioprodutivas dos agricultores do bairro Bacuri

\begin{tabular}{|c|c|c|c|c|c|c|c|c|}
\hline $\begin{array}{l}\text { Agricultor } \\
\text { Urbano }\end{array}$ & $\begin{array}{c}\text { Está } \\
\text { associado a } \\
\text { cooperativa } \\
\text { ou } \\
\text { associação? }\end{array}$ & $\begin{array}{c}\text { O que } \\
\text { proporciona a } \\
\text { cooperativa } \\
\text { ou } \\
\text { associação? }\end{array}$ & $\begin{array}{c}\text { A } \\
\text { agricultura } \\
\text { é sua } \\
\text { atividade } \\
\text { exclusiva } \\
\text { ou parcial? } \\
\end{array}$ & $\begin{array}{l}\text { Já buscou } \\
\text { assistência } \\
\text { técnica? }\end{array}$ & $\begin{array}{l}\text { Em qual } \\
\text { instituição } \\
\text { buscou } \\
\text { assistência } \\
\text { técnica? }\end{array}$ & $\begin{array}{l}\text { Já } \\
\text { procurou } \\
\text { crédito } \\
\text { agrícola? }\end{array}$ & $\begin{array}{l}\text { Em qual } \\
\text { instituição } \\
\text { buscou } \\
\text { crédito } \\
\text { agrícola? }\end{array}$ & $\begin{array}{c}\text { Para } \\
\text { qual } \\
\text { projeto }\end{array}$ \\
\hline AUB1 & $\begin{array}{c}\text { Sim } \\
\text { (Líder) }\end{array}$ & $\begin{array}{l}\text { Programas } \\
\text { como PAA }\end{array}$ & Exclusiva & Sim & Sebrae & Sim & $\begin{array}{l}\text { Banco do } \\
\text { Nordeste }\end{array}$ & $\begin{array}{l}\text { Agro } \\
\text { amig }\end{array}$ \\
\hline AUB2 & Sim & $\begin{array}{l}\text { Programas } \\
\text { como PAA }\end{array}$ & Exclusiva & Sim & $\begin{array}{c}\begin{array}{c}\text { Sebrae } \\
\text { (cursos) }\end{array} \\
\end{array}$ & Sim & $\begin{array}{l}\text { Banco do } \\
\text { Nordeste }\end{array}$ & $\begin{array}{l}\text { Agro } \\
\text { amig } \\
\end{array}$ \\
\hline$A \cup B 3$ & Não & - & Exclusiva & Não & - & Não & - & - \\
\hline AUB4 & Sim & - & Exclusiva & Não & - & Não & - & - \\
\hline AUB5 & Sim & PAA & Exclusiva & $\mathrm{Sim}$ & Sebrae & Não & - & - \\
\hline AUB6 & Não & - & Exclusiva & Não & - & Não & - & - \\
\hline AUB7 & Não & - & Exclusiva & Não & - & Não & - & - \\
\hline AUB8 & Não & - & Exclusiva & Não & - & Não & - & - \\
\hline AUB9 & Não & - & Exclusiva & Não & - & Não & - & - \\
\hline AUB10 & Sim & $\begin{array}{l}\text { Programas } \\
\text { de créditos }\end{array}$ & Exclusiva & Sim & - & Sim & $\begin{array}{l}\text { Banco do } \\
\text { Nordeste }\end{array}$ & $\begin{array}{l}\text { Agro } \\
\text { amig }\end{array}$ \\
\hline AUB11 & Não & - & $\begin{array}{c}\text { Parcial } \\
\text { (Vigilante }\end{array}$ & Não & - & Não & - & - \\
\hline AUB12 & Sim & PAA & Exclusiva & Não & - & Não & - & - \\
\hline
\end{tabular}

Fonte: elaborado pelos autores

Com relação aos produtores agrícolas do bairro Vila Nova, do total de entrevistados $83 \%$ não estão associados a alguma cooperativa ou associação. As características socioprodutivos desses agricultores estão demonstradas no Quadro 5 . 
Quadro 5 - Características socioprodutivos dos agricultores Vila Nova

\begin{tabular}{|c|c|c|c|c|c|c|c|c|}
\hline $\begin{array}{l}\text { Agricultor } \\
\text { Urbano }\end{array}$ & $\begin{array}{c}\text { Está } \\
\text { associado a } \\
\text { cooperativa } \\
\text { ou } \\
\text { associação? }\end{array}$ & $\begin{array}{c}\text { O que } \\
\text { proporciona a } \\
\text { cooperativa } \\
\text { ou } \\
\text { associação? }\end{array}$ & $\begin{array}{c}\text { A } \\
\text { agricultura } \\
\text { é sua } \\
\text { atividade } \\
\text { exclusiva } \\
\text { ou parcial? }\end{array}$ & $\begin{array}{l}\text { Já buscou } \\
\text { assistência } \\
\text { técnica? }\end{array}$ & $\begin{array}{l}\text { Em qual } \\
\text { instituição } \\
\text { buscou } \\
\text { assistência } \\
\text { técnica? }\end{array}$ & $\begin{array}{l}\text { Já } \\
\text { procurou } \\
\text { crédito } \\
\text { agrícola? }\end{array}$ & $\begin{array}{l}\text { Em qual } \\
\text { instituição } \\
\text { buscou } \\
\text { crédito } \\
\text { agrícola? }\end{array}$ & $\begin{array}{c}\text { Para qual } \\
\text { projeto? }\end{array}$ \\
\hline$A U V_{1}$ & $\begin{array}{l}\text { Sim } \\
\text { (Líder) }\end{array}$ & $\begin{array}{l}\text { Crédito } \\
\text { agrícola, } \\
\text { PAA }\end{array}$ & Exclusiva & Sim & $\begin{array}{c}\text { Sebrae/ } \\
\text { Senar }\end{array}$ & Sim & $\begin{array}{c}\text { Banco } \\
\text { Nordeste }\end{array}$ & $\begin{array}{l}\text { Agro } \\
\text { amigo }\end{array}$ \\
\hline AUV2 & Não & - & Exclusiva & Sim & $\begin{array}{l}\text { Imperagro/ } \\
\text { Eng. } \\
\text { Agrônomo }\end{array}$ & Não & - & - \\
\hline $\mathrm{AUV}_{3}$ & Sim & Só pago & Exclusiva & Sim & Sebrae & Sim & $\begin{array}{c}\text { Banco } \\
\text { Nordeste }\end{array}$ & $\begin{array}{l}\text { Cred } \\
\text { amigo }\end{array}$ \\
\hline $\mathrm{AUV}_{4}$ & Não & - & Exclusiva & Não & - & Não & - & - \\
\hline$A_{U} V_{5}$ & Não & - & Exclusiva & Sim & Sebrae & Não & - & - \\
\hline AUV6 & Não & & Exclusiva & Sim & Sebrae/Senar & Sim & $\begin{array}{c}\text { Banco } \\
\text { Nordeste }\end{array}$ & $\begin{array}{l}\text { Agro } \\
\text { amigo }\end{array}$ \\
\hline AUV7 & Não & - & Exclusiva & Não & $\begin{array}{c}\text { Sou } \\
\text { Engenheiro } \\
\text { Agrônomo }\end{array}$ & Sim & $\begin{array}{c}\text { Banco } \\
\text { Nordeste }\end{array}$ & $\begin{array}{c}\text { Cadastro } \\
\text { negado }\end{array}$ \\
\hline AUV8 & Não & - & Exclusiva & Sim & Sebrae & Não & - & - \\
\hline AUV9 & Não & - & Exclusiva & Sim & Sebrae & Sim & $\begin{array}{c}\text { Banco } \\
\text { Nordeste }\end{array}$ & $\begin{array}{l}\text { Agro } \\
\text { amigo }\end{array}$ \\
\hline AUV10 & Não & - & Exclusiva & Sim & Sebrae/ Senar & Não & - & - \\
\hline AUV11 & Não & - & Exclusiva & Sim & Sebrae & Não & - & - \\
\hline AUV12 & Não & - & Exclusiva & Sim & Sebrae/ Senar & Não & - & - \\
\hline
\end{tabular}

Fonte: elaborado pelos autores

$\mathrm{O}$ agricultor $\mathrm{AUV}_{3}$ ressaltou que contribui com o pagamento à associação, mas nunca a utilizou, pois, sua produção é muito grande e se for contribuir para outros programas com os quais a Associação quer realizar cadastros, pode prejudicar os abastecimentos que executa.

Já AUV1, que no momento é o líder da associação, explica que "tinha bastante gente associada, mas devido alguns problemas políticos uma turma ai decidiu não participar mais, então vamos adiante tentando trazer eles de volta, pois só conseguimos alguma coisa junto".

Apesar de uma pequena parcela participar de associação, é possível diagnosticar a presença de um líder, identificando o código indicador de análise (mudanças).

Dos entrevistados, 83\% destacaram a busca de assistência técnica de órgãos com Sebrae ou Senar, de acordo com os dados abordados na Quadro 5, caracterizando o código indicador (Planos), em que o sensemaking está aliado à previsão, guiando futuras ações.

É importante salientar que agricultores como AUV2 preferem buscar ajuda técnica em empresas nas quais compram seus produtos ou até mesmo solicitar ajuda ao engenheiro agrônomo AUV7, que também é agricultor na área e sempre contribui na produção.

Com relação ao crédito agrícola, $42 \%$ dos entrevistados procuraram no Banco do Nordeste para projetos como Agroamigo (Programa de Microcrédito Produtivo Orientado) e Credamigo (Programa de Microfinanças Rural do Banco do Nordeste), 
característica essa identificada no código indicador (Planos), em que Sensemaking está aliado à previsão e guia futuras ações.

Quanto ao bairro Planalto, 100\% não estão associados a alguma cooperativa ou associação, mas $42 \%$ buscaram assistência técnica para a produção agrícola. $O$ Sebrae é a instituição mais procurada (Quadro 6).

Com relação ao código indicador (mudanças), o Sensemaking identifica uma ação objetiva. No bairro Planalto não há uma liderança definida no grupo, com possibilidade menor de mudanças na organização, identificando individualidade, algo já encontrado em outros resultados do sensemaking.

Já em relação ao crédito agrícola, os agricultores também buscaram apoio no Banco do Nordeste para participação em programas como Agroamigo e Credamigo, conforme dados do Quadro 6, que traz as características socioprodutivas dos agricultores do bairro Planalto.

Ao analisar todos os Quadros referentes aos três bairros que possuem agricultura urbana, pode-se confirmar que ela se caracteriza nesses grupos como uma atividade exclusiva, com exceção de três agricultores que atuam em outra atividade buscando um complemento da renda familiar.

Quadro 6 - Características socioprodutivos dos agricultores bairro Planalto

\begin{tabular}{|c|c|c|c|c|c|c|c|c|}
\hline $\begin{array}{l}\text { Agricultor } \\
\text { Urbano }\end{array}$ & $\begin{array}{c}\text { Está } \\
\text { associado a } \\
\text { cooperativa } \\
\text { ou } \\
\text { associação? }\end{array}$ & $\begin{array}{c}\text { O que } \\
\text { proporciona a } \\
\text { cooperativa ou } \\
\text { associação? }\end{array}$ & $\begin{array}{l}\text { A agricultura é } \\
\text { sua atividade } \\
\text { exclusiva ou } \\
\text { parcial? }\end{array}$ & $\begin{array}{l}\text { Já buscou } \\
\text { assistênci } \\
\text { a técnica? }\end{array}$ & $\begin{array}{l}\text { Em qual } \\
\text { instituição } \\
\text { buscou } \\
\text { assistência } \\
\text { técnica? }\end{array}$ & $\begin{array}{l}\text { Já } \\
\text { procurou } \\
\text { crédito } \\
\text { agrícola? }\end{array}$ & $\begin{array}{c}\text { Em qual } \\
\text { instituição } \\
\text { buscou crédito } \\
\text { agrícola? }\end{array}$ & $\begin{array}{l}\text { Para qual } \\
\text { projeto? }\end{array}$ \\
\hline AUP1 & Não & - & Exclusiva & Não & Não & Sim & $\begin{array}{c}\text { Banco } \\
\text { Nordeste }\end{array}$ & $\begin{array}{l}\text { Agro } \\
\text { amigo }\end{array}$ \\
\hline AUP2 & Não & - & Exclusiva & Não & Não & Não & - & - \\
\hline $\mathrm{AUP}_{3}$ & Não & - & Exclusiva & Não & Não & Não & - & - \\
\hline AUP4 & Não & - & Exclusiva & Sim & Sebrae & Não & - & - \\
\hline AUP5 & Não & - & Exclusiva & Não & - & Não & - & - \\
\hline AUP6 & Não & - & Exclusiva & Sim & Sebrae & Não & - & - \\
\hline AUP7 & Não & - & $\begin{array}{c}\text { Parcial } \\
\text { vigilante }\end{array}$ & Não & - & Sim & $\begin{array}{c}\text { Banco } \\
\text { Nordeste }\end{array}$ & $\begin{array}{c}\text { Cred } \\
\text { amigo }\end{array}$ \\
\hline AUP8 & Não & - & $\begin{array}{c}\text { Parcial } \\
\text { vigilante }\end{array}$ & Sim & Sebrae & Sim & $\begin{array}{c}\text { Banco } \\
\text { Nordeste }\end{array}$ & $\begin{array}{c}\text { Agro } \\
\text { amigo }\end{array}$ \\
\hline AUPg & Não & - & Exclusiva & Sim & Sebrae & Não & & \\
\hline AUP10 & Não & - & Exclusiva & Sim & Sebrae & Sim & $\begin{array}{c}\text { Banco } \\
\text { Nordeste }\end{array}$ & $\begin{array}{c}\text { Cred } \\
\text { amigo }\end{array}$ \\
\hline AUP11 & Não & - & Exclusiva & Não & - & Não & - & - \\
\hline AUP12 & Não & - & Exclusiva & Não & - & Não & - & - \\
\hline
\end{tabular}

Fonte: elaborado pelos autores

O resultado da pesquisa com relação à atuação na atividade não se assemelha às características citadas por Mougeot (2000), quando ressalta que a agricultura urbana é uma atividade secundária com participação parcial, pois a 
pesquisa identificou-a entre os entrevistados como uma atividade com participação integral, uma característica da agricultura rural e não urbana, possivelmente justificada pelo resultado da migração de outro estado ou região onde o entrevistado atuava com a agricultura rural.

O fato de a atuação da agricultura urbana ser uma atividade exclusiva, diferente do que ressalta o referencial, é justificável quando Campilan et al. (2002) citam que a agricultura urbana é identificada também como uma atividade de migrantes de áreas rurais, o que acontece com 69\% dos entrevistados que sempre atuaram na agricultura e migraram de outros interiores e outros estados para áreas urbanas e que continuaram a executar a atividade que aprenderam com suas famílias, justificando o resultado quanto à abordagem direcionada à atividade exclusiva.

O diagnóstico referente ao destino da colheita dos entrevistados mostra que a agricultura contribui na renda familiar e há uma diminuição nos gastos, visto que uma parte da produção se destina à alimentação da própria família e a outra parte à comercialização, conforme os Quadros 7, 8 e 9 que se referem ao destino da colheita dos bairros Bacuri, Vila Nova e Planalto respectivamente.

Para Aquino e Assis (2007), é visível os resultados e pontos positivos que a agricultura urbana pode proporcionar aos atores diretamente envolvidos na atividade, de forma a contribuir com a melhoria da renda das famílias produtoras que participam direta e indiretamente, visando à produção e qualidade da matériaprima elaborada para propiciar a ocupação de áreas improdutivas no espaço urbano.

Conforme dados do Quadro 7, os agricultores do bairro Bacuri recebem encomendas da maioria dos revendedores por venda direta, e em seguida encaminham os produtos para o transporte e entrega com exceção daqueles que fornecem ao banco de alimentos e escolas e têm que se organizar para fazer a entrega.

Segundo AUB5, ela mesma faz a entrega: "Eu pego minha bicicletinha e eu vou lá deixar as coisas, se não outros vão lá e vende, e eles já sabem que toda semana tenho meu dia de entrega. Tenho preguiça não".

Dentre os agricultores, $75 \%$ repassam a colheita para sacolões, feirantes e mercearias e $25 \%$ vendem no próprio local de cultivo, banca e casa. Desses $75 \%$, uma agricultora, $A \cup B 7$, iniciou no ano de 2017 o fornecimento para o hospital municipal. 
Quadro 7 - Destino da colheita bairro Bacuri

\begin{tabular}{|c|l|}
\hline $\begin{array}{c}\text { Agricultores do } \\
\text { Bairro Bacuri }\end{array}$ & \multicolumn{1}{c|}{ Qual o destino de sua colheita? } \\
\hline AUB1 & Sacolões, mercearias, feirantes \\
\hline AUB2 & Banco de alimentos, sacolões e tenho contrato com um supermercado \\
\hline AUB3 & Escolas, banco de alimentos, sacolões \\
\hline AUB4 & $\begin{array}{l}\text { Vendo aqui mesmo na própria horta (vem muito cliente aqui e já tenho meus } \\
\text { clientes) }\end{array}$ \\
\hline AUB5 & Feira, mercadinho, sacolões, banco de alimentos \\
\hline AUB6 & Tenho uma banca na porta da minha casa \\
\hline AUB7 & Hospital Municipal \\
\hline AUB8 & Sacolões, mercearias, feirantes, mercadinho (tenho uma banca no mercadinho) \\
\hline AUB9 & Feira e mercadinho \\
\hline AUB10 & Sacolões e supermercados do bairro \\
\hline AUB11 & Venda na própria horta \\
\hline AUB12 & Sacolões, mercearias, feirantes \\
\hline
\end{tabular}

Fonte: elaborado pelos autores

As agricultoras AUB4 e AUB11 têm uma clientela muito grande no bairro e suas vendas são feitas somente na área de produção, exposta na Figura 3, onde alguns feirantes compram para revender. AUB6 só tem uma banca em casa e já é aposentado.

As Figuras 3 e 4 ilustram a produção urbana no bairro Bacuri.

Figura 3 - Agricultura urbana bairro Bacuri

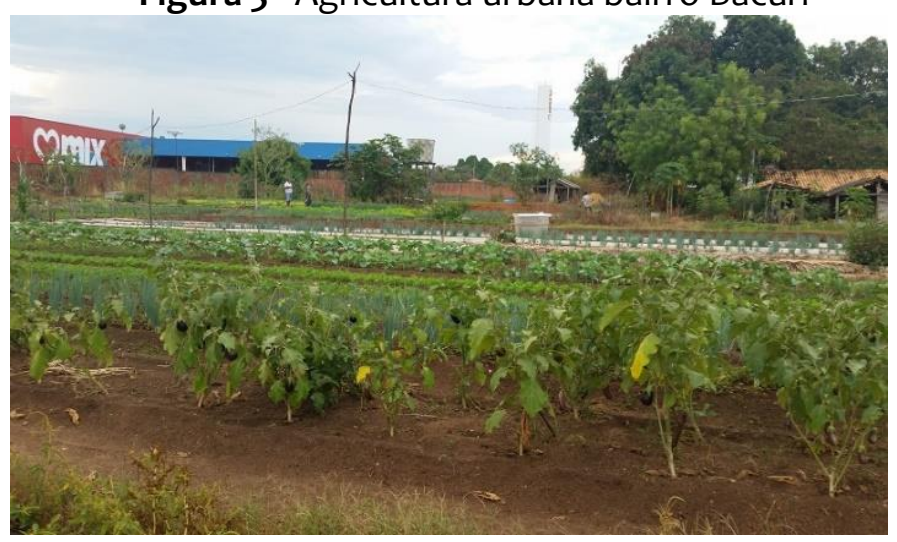

Na Figura 4, a seguir, visualiza-se a área produtiva e suas variedades na ocupação do espaço do bairro Bacuri, assim como a organização e separação por lotes destinados a cada produtor. 


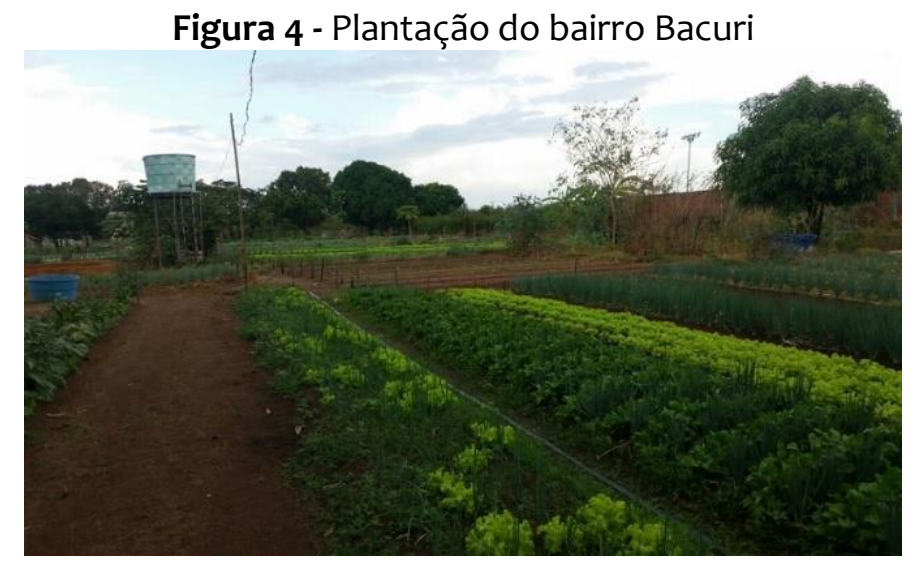

Quanto ao destino da colheita do bairro Vila Nova, conforme Quadro 8, 100\% afirmam repassar a colheita para supermercados, feiras, restaurantes e hospitais. Os produtores AUV2, AUV 3 e AUV7 fazem diferença no aspecto econômico do município de Imperatriz, pois têm um índice de produção muito alto na região.

São responsáveis por grande parte do abastecimento da maior rede de supermercados do Maranhão e ainda atendem às regiões circunvizinhas, outros municípios e até outros estados, como ressalta o agricultor AUV3.

É importante salientar que o bairro Vila Nova é o local onde se concentra a maior área de agricultura urbana do município, o que justifica a fala de Mougeot (2006), quando o cita que a agricultura urbana movimenta a economia local, influenciando no desenvolvimento.

Quadro 8 - Destino da colheita bairro Vila Nova

\begin{tabular}{|c|l|}
\hline Bairro Vila Nova & \multicolumn{1}{c|}{ Qual o destino de sua colheita } \\
\hline AUV1 & Programa PAA, merenda escolar \\
\hline AUV2 & Quatro supermercados Matheus, mercadinho, feirinha \\
\hline AUV3 & $\begin{array}{l}\text { Supermercados Matheus e todos os supermercados Matheus das regiões de } \\
\text { colinas, Açailândia e Marabá e supermercado Santa Maria em Açailândia. }\end{array}$ \\
\hline AUV4 & Mercadinho \\
\hline AUV5 & Banco de alimentos, Praça de Fátima, feirinha e mercadinho \\
\hline AUV6 & Feirinhas, mercadinho e tenho uma banca na feirinha \\
\hline AUV7 & Supermercados Matheus, restaurantes, feirantes, cidades circunvizinhas \\
\hline AUV8 & Praça de Fátima, feirinha e mercadinho \\
\hline AUV9 & Feirantes e Mercadinho \\
\hline AUV10 & Restaurantes, Praça de Fátima e Feirinha (tenho uma banca) \\
\hline AUV11 & Supermercados do bairro e sacolões \\
\hline AUV12 & Restaurantes e hospital particular \\
\hline
\end{tabular}

Fonte: elaborado pelos autores

Ao conhecer a produção urbana desses agricultores que se encontram há muito tempo naquela área é possível diagnosticar que há um histórico de muita paixão e respeito pela área na qual estão atuando.

Por conta de sua paixão à agricultura fazem com que na atualidade o município de Imperatriz tenha condições de fornecer esse tipo de produção sem precisar que venha de outros estados. 
Assim se manifesta AUV3:

Eu conheci a agricultura por conta da minha mulher. A mãe dela foi as primeiras que chegou aqui e criou ela aqui nessa área e quando conheci já existia essa produção que atendia o maior supermercado na época que se chamava "Timbiras supermercado, ai quando eu casei com minha mulher, minha sogra morreu e eu tive que continuar o trabalho dela e graças a Deus posso dizer que somos os maior produtor da região. Mais não foi fácil não, tivemos que investir para aumentar a produção, coisa que poucos fazem por aqui, porque fica esperando ajuda de política (AUV3, 2017).

Outro agricultor que tem um grande destaque nessa área é AUV7. É engenheiro agronômico e fornece sua colheita para grandes supermercados, outros municípios e estados. Ressalta a sua dedicação pela atuação na agricultura e tem os mesmos cuidados que AUV2 e AUV3.

Como citam Aquino e Monteiro (2005), a produção dos agricultores urbanos está diretamente ligada a vários setores agrícolas. É utilizada de forma diversa para atender à subsistência e comercialização, podendo atingir diferentes áreas por apresentar uma diversidade de atividades englobadas em um mesmo contexto.

O bairro Vila Nova tem grande destaque na produção agrícola urbana pelo fato de ter feito parte de um projeto criado em 2001 no entorno do aeroporto de Imperatriz (MA). O projeto integrou um programa realizado pela Empresa Brasileira de Infraestrutura Aeroportuária (INFRAERO), ao qual atribuíram o nome de Cinturão Verde.

O projeto teve como objetivo melhorar o trabalho de pequenos produtores com a produtividade e qualidade da horticultura, visando o aumento da produção agrícola familiar, proporcionando ações para a melhoria da produção e comercialização, e hoje é uma das maiores áreas de produção agrícola urbana da região (INFRAERO, 2016).

O projeto foi desenvolvido com parceria com a Empresa Brasileira de Pesquisa Agropecuária (Embrapa), Serviço Brasileiro de Apoio às Micros e Pequenas Empresas (Sebrae), além da Universidade Estadual do Maranhão em conjunto com a Empresa Brasileira de Infraestrutura Aeroportuária (Infraero).

Com as parcerias foi possível desenvolver uma infraestrutura com estufas apropriadas para a produção das mudas em bandejas; estruturas para o processo de compostagem e canteiros para a pesquisa com hortaliças, que seriam utilizados pelas universidades como locais para aulas práticas em cursos que necessitavam de uma área de estudo (INFRAERO, 2016). Dessa forma, justifica-se a melhor estrutura do bairro Vila Nova quando comparada aos outros bairros.

Em 2009, em virtude do crescimento da agricultura urbana que acontecia na região do bairro Vila Nova e havendo a necessidade de aumentar a produção para outras localidades, os órgãos envolvidos no projeto decidiram expandi-lo para vários bairros, como Ouro Verde, Santa Inês, Vila Vitória, Planalto e Parque Santa Lúcia.

Com o projeto aumentou a produtividade em zonas urbanas e periurbanas do município, justificando as respostas de alguns produtores do bairro Planalto quando citam que receberam assistência técnica, referindo-se ao Sebrae. 
Nolasco (2016), em seu trabalho, ressalta a demanda e abastecimentos de hortaliças no Brasil apesar das limitações encontradas na produção, principalmente quando se trata da posse da terra.

O autor aponta o aumento significativo da demanda de hortaliças no meio urbano, principalmente nos estados do Nordeste e Norte, o que justifica o crescimento da agricultura no Maranhão, um dos estados que Nolasco (2016) destacou quanto ao aumento da densidade de produção de hortaliças no estado.

O bairro Bacuri não se encontra entre os beneficiados com auxílio, assistência técnica ou apoio de projetos, como já citado. Isso talvez pelo fato de $67 \%$ dos entrevistados não buscarem esses recursos.

Contrariamente, $83 \%$ dos entrevistados do bairro Vila Nova buscaram assistência e faziam parte do projeto da Infraero. No bairro Planalto, com a expansão da agricultura urbana, $42 \%$ dos produtores buscaram assistência técnica.

Nolasco (2016) destaca que com o crescimento da demanda de hortaliças no Brasil, há relatos de falta de assistência técnica, dificuldade de acesso a maquinário, ao crédito ou subsídios para melhoria na propriedade, o que não se diferencia da presente pesquisa.

O projeto, segundo a Infraero (2016), estimulou várias assistências tanto técnicas como vários cursos que incentivam os moradores produtores com cursos técnicos, palestras envolvendo temáticas como cidadania, educação e conservação ambiental, além de treinamento com empresas como Sebrae, com o objetivo de melhorar a qualidade de vida e justificando o início do crescimento da agricultura urbana no município de Imperatriz.

Desde 2015 o projeto encontra-se parado. Há somente um acordo de arrendamento entre os produtores e a Empresa Brasileira de Infraestrutura Aeroportuária (INFRAERO) em relação ao terreno onde os agricultores ainda mantêm sua produção.

Apesar de o projeto não estar ativo desde 2015, por conta de mudanças externas na Infraero, encontra-se em negociação conforme ressalta AUV3, líder da associação dos agricultores do bairro Planalto. Os entrevistados do bairro Vila Nova reconhecem o apoio das empresas quando se trata do crescimento da agricultura no município.

Com o projeto, os agricultores do bairro Vila Nova tiveram auxílio no abastecimento de água com a construção de poços para o funcionamento das hortas. AUP3, que tem casa na horta, citou que a água também vem da rua e cada agricultor paga sua respectiva conta do abastecimento para a plantação e para a casa, o que acontece também no bairro Planalto, e não informada pelos agricultores do bairro Bacuri.

As Figuras 5 e 6 mostram a produção dos agricultores urbanos do bairro Vila Nova. 
Figura 5 - Agricultura urbana bairro Vila Nova

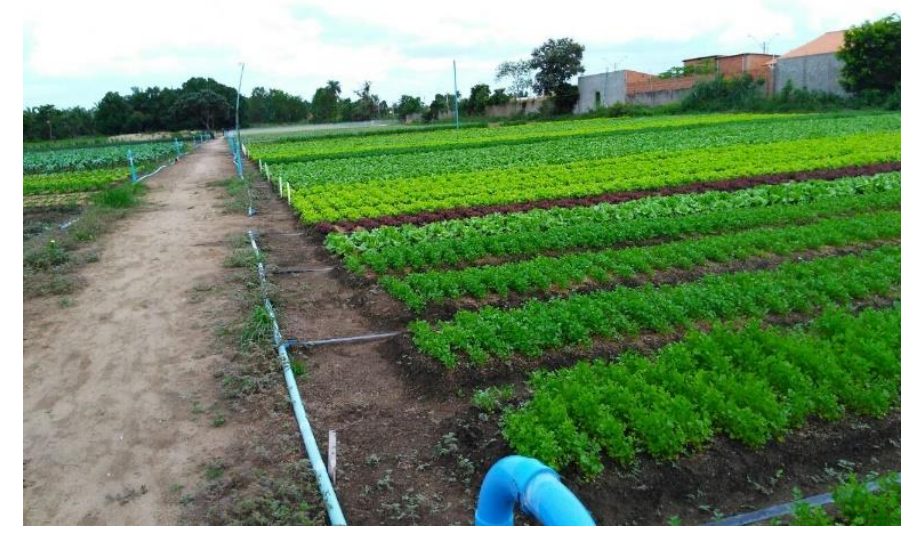

Figura 6- Estufa de preparação de mudas bairro Vila Nova

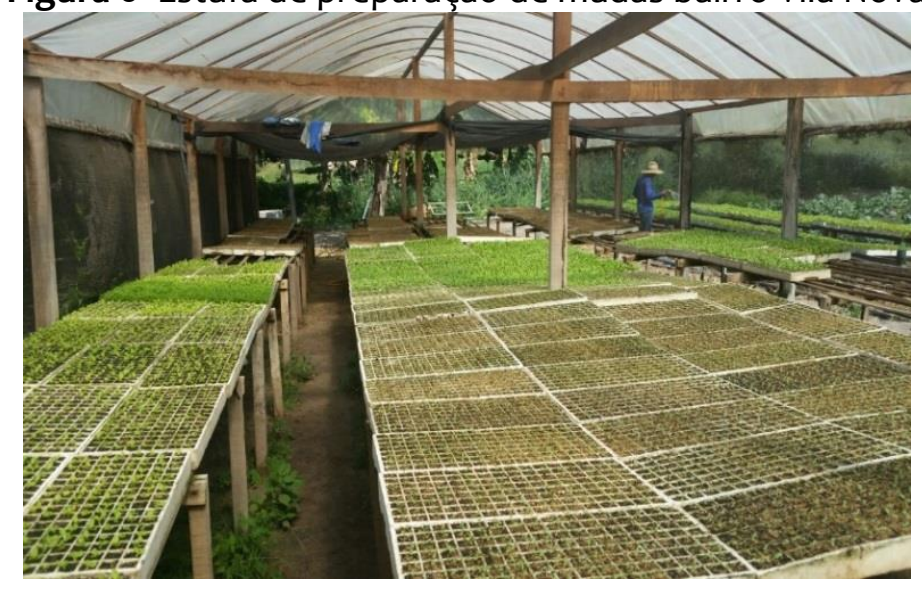

É possível visualizar os investimentos em materiais, estufas e a utilização de toda a área arrendada, assim como a variedade na produção. A agricultura urbana do bairro Vila Nova, conforme dados da pesquisa, é a maior atuação de agricultura urbana no município de Imperatriz (MA), conforme as Figuras 7 e 8.

Figura 7 - Reservatório de água bairro Vila Nova

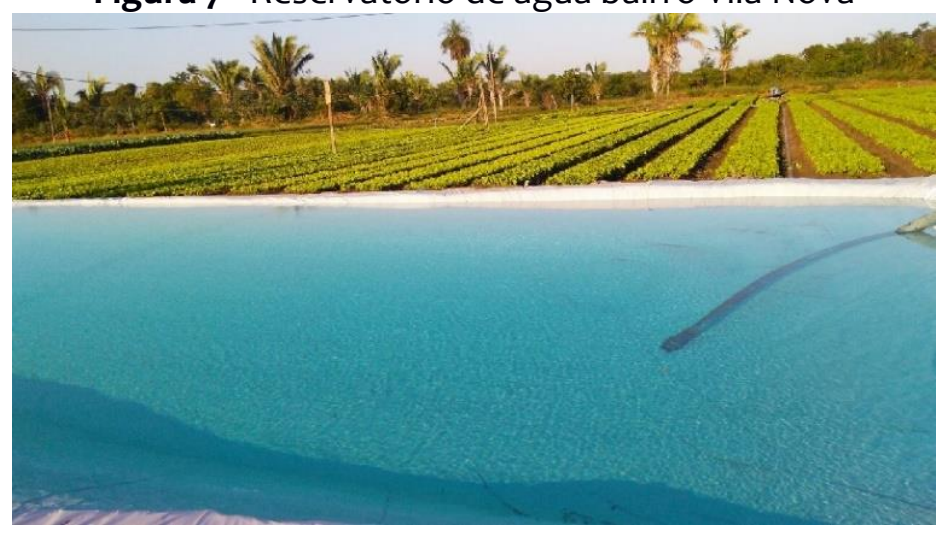




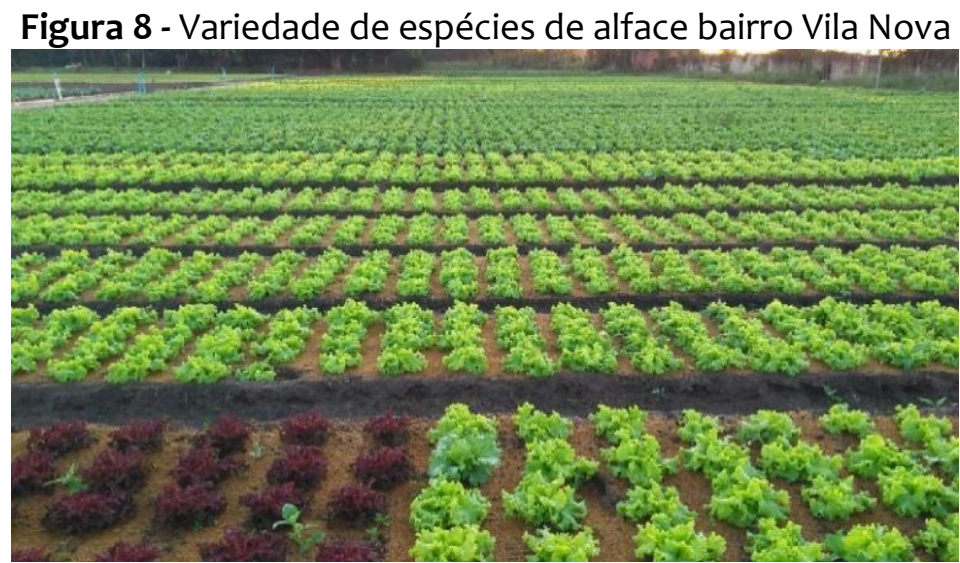

Os agricultores AUV3 e AUV7, no que diz respeito à forma de comercialização, são os únicos que fazem transporte das mercadorias, por ter carros apropriados e eles próprios fazerem o devido transporte.

AUV2, por sua vez, apesar de ter uma produção muito grande não faz a distribuição, e quando fecha algum contrato uma das atividades que ele não executa é o transporte. Alega que tem uma clientela grande e seria mais um gasto contratar alguém para fazer a entrega. Ele não dirige e já conseguiu com que sua clientela se acostumasse a buscar a mercadoria.

Além desses agricultores, o bairro Vila Nova tem outro grupo que fornece seus produtos ao PAA, mercadinho, feirinhas, praça de Fátima e banco de alimentos. Outros, como AUV6 e AUV10, têm bancas em feiras e vendem sua própria produção.

Quanto ao destino da colheita dos agricultores do bairro Planalto, conforme o Quadro 9, grande parte segue para supermercados da região, assim como para mercearias e sacolões, com exceção dos agricultores AUP1, que além das vendas já ressaltadas também tem uma banca na feira, e AUP10, que tem um sacolão em casa.

Quadro 9 - Destino da colheita do bairro Planalto

\begin{tabular}{|c|l|}
\hline Bairro Planalto & \multicolumn{1}{c|}{ Qual o destino de sua colheita } \\
\hline AUP1 & Mercearias, sacolões, feiras e banca na feirinha \\
\hline AUP2 & Supermercados aqui do bairro e sacolões \\
\hline AUP3 & Na própria horta, mercadinho e feirinhas \\
\hline AUP4 & Venda aqui mesmo na horta \\
\hline AUP5 & Sacolão e mercados do bairro \\
\hline AUP6 & Venda aqui mesmo na horta \\
\hline AUP7 & Feirantes e mercadinho \\
\hline AUP8 & Pessoas que vendem na rua e feirantes \\
\hline AUP9 & Feirantes e na própria horta \\
\hline AUP10 & Tenho um sacolão em casa \\
\hline AUP11 & Feirantes e na própria horta (já temos o nosso público) \\
\hline AUP12 & Sacolão e supermercado do bairro \\
\hline
\end{tabular}

Fonte: elaborado pelos autores

Dos entrevistados, 33\% repassam a colheita somente para mercadinhos, feiras, sacolões e supermercados e $67 \%$ vendem na própria propriedade e em feiras. Os agricultores ressaltam que parte dos fornecedores acabam indo buscar no local 
de produção e que supermercados da região já deixam reservados alguns canteiros exclusivos para a venda. Dessa forma, o agricultor já sabe a venda certa que terá que produzir, além de moradores que vão diretamente comprar onde se cultiva.

Nas Figuras 9 e 10 é possível conhecer um pouco do trabalho e organização dos agricultores urbanos do bairro Planalto.
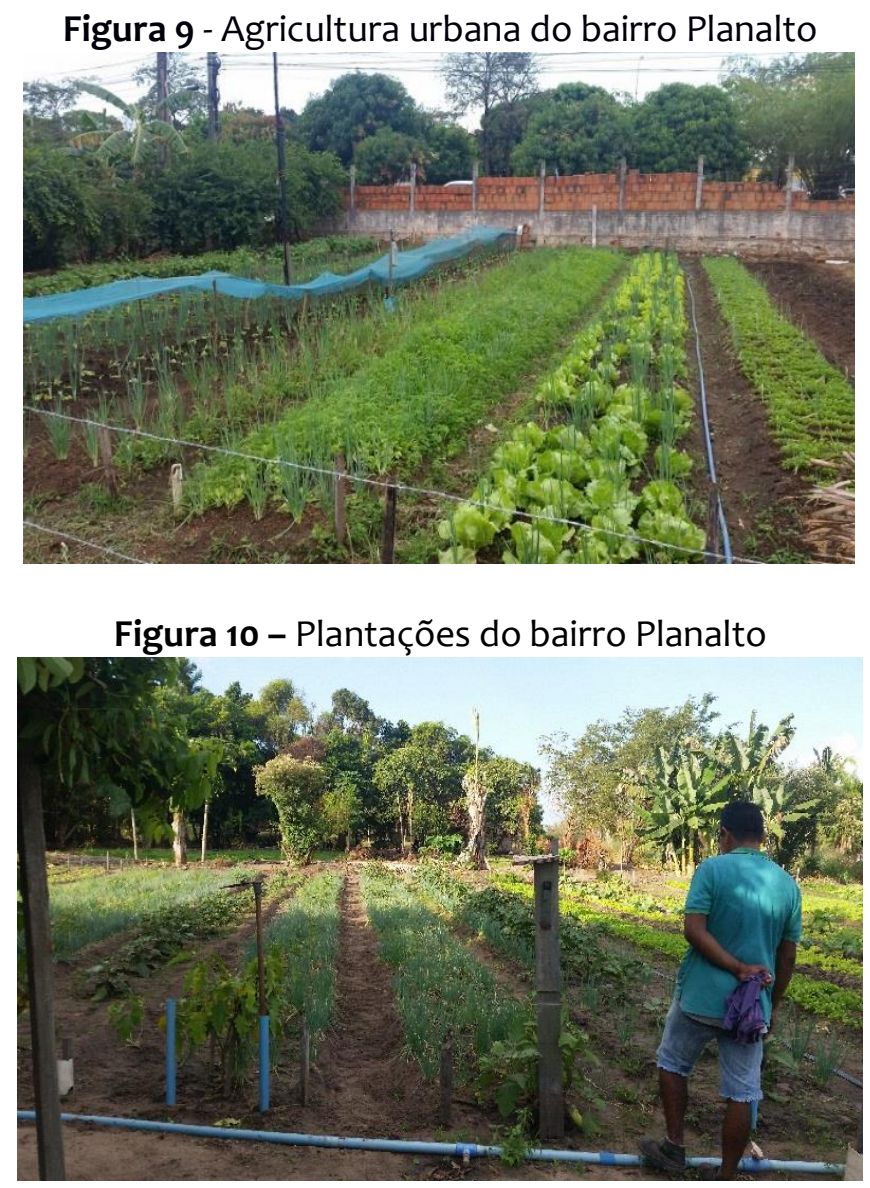

\subsection{Utilização de agroquímicos}

O que constantemente se discute nas produções agrícolas é a produção livre de resíduos químicos. Por esse motivo, foram elaboradas perguntas que questionavam o uso de agroquímicos, conforme Quadro 10, que retrata a sua utilização de agroquímicos no bairro Bacuri.

Os produtores do bairro Bacuri, conforme Quadro 10, não utilizam nenhum produto químico e justificaram outras maneiras para combater as pragas: $17 \%$ não adotam qualquer procedimento; $50 \%$ utilizam solução de pimenta, álcool e sabão de coco, enquanto $33 \%$ utilizam o controle com outras plantas, técnica chamada 'cultura armadilha', que eles designam 'outras plantas'. Significa plantar algumas espécies de plantas ao redor do local da plantação, para que essas plantas atraiam as pragas para si. 
Quadro 10 - Utilização de agroquímicos no bairro Bacuri

\begin{tabular}{|c|c|c|c|c|c|}
\hline Agricultor & $\begin{array}{l}\text { Há utilização de } \\
\text { agroquímicos? }\end{array}$ & $\begin{array}{l}\text { Como ocorre o } \\
\text { controle de pragas e } \\
\text { plantas invasoras? }\end{array}$ & $\begin{array}{l}\text { Recomendação } \\
\text { feita por } \\
\text { técnico? }\end{array}$ & $\begin{array}{l}\text { Utiliza equipamento } \\
\text { de proteção? }\end{array}$ & $\begin{array}{c}\text { Recebeu alguma } \\
\text { orientação com relação } \\
\text { aos equipamentos de } \\
\text { proteção? }\end{array}$ \\
\hline AUB1 & Não & Com outras plantas & - & Sim & Não \\
\hline AUB2 & Não & $\begin{array}{l}\text { Solução de pimenta, } \\
\text { álcool e sabão de coco }\end{array}$ & - & Sim & Não \\
\hline $\mathrm{AUB}_{3}$ & Não & $\begin{array}{l}\text { Não faço nada, minha } \\
\text { terra é boa }\end{array}$ & - & Sim & Não \\
\hline AUB4 & Não & Com outras plantas & - & Sim & Não \\
\hline AUB5 & Não & $\begin{array}{l}\text { Solução de pimenta, } \\
\text { álcool e sabão de coco }\end{array}$ & - & Nenhuma proteção & Não \\
\hline AUB6 & Não & $\begin{array}{l}\text { Solução de pimenta, } \\
\text { álcool e sabão de coco }\end{array}$ & - & Nenhuma proteção & Não \\
\hline AUB7 & Não & $\begin{array}{l}\text { Solução de pimenta, } \\
\text { álcool e sabão de coco }\end{array}$ & - & Sim & Não \\
\hline AUB8 & Não & $\begin{array}{l}\text { Não faço nada, minha } \\
\text { terra é boa }\end{array}$ & - & Sim & Não \\
\hline AUB9 & Não & Com outras plantas & - & Sim & Não \\
\hline AUB10 & Não & $\begin{array}{l}\text { Solução de pimenta, } \\
\text { álcool e sabão de coco }\end{array}$ & - & Sim & Não \\
\hline AUB11 & Não & $\begin{array}{l}\text { Solução de pimenta, } \\
\text { álcool e sabão de coco }\end{array}$ & - & Sim & Não \\
\hline AUB12 & Não & Com outras plantas & - & Nenhuma proteção & Não \\
\hline
\end{tabular}

Fonte: elaborado pelos autores

A maioria dos agricultores usam um produto natural para o controle de pragas, que vem da aprendizagem dos pais dos agricultores AUB5 e AUB6, elaborado a partir da mistura de álcool, pimenta e sabão de coco. Segundo os agricultores, funciona plenamente.

AUB2 ressalta que seguiu a aprendizagem dos que trabalham há mais tempo na área e utiliza esse produto, que somente é aplicado quando existe algum indício de pragas no local. Há também aqueles que não utilizam nada para controlar as pragas: suas terras são resistentes, conforme destacam AUB3 e AUB8.

Quanto à utilização de proteção durante a execução das atividades, 67\% utilizam equipamentos de proteção individual, como como botas, chapéus e blusas de mangas longas. Dentre os 33\% que não usam está AUB6, que diz já ter se acostumado, mas todos reconhecem a necessidade e os problemas que podem ser ocasionados ao não se protegerem de alguma forma.

Apesar de a maioria utilizar equipamento de proteção e não ter nenhuma orientação quanto a esses equipamentos, ou não utilizar agroquímicos, é necessário destacar que uma simples camisa ou bota é considerado material de proteção, seja para combater o Sol ou proteger os pés.

Esses itens, considerados de proteção, não protegem na utilização de agroquímicos e os agricultores não tiveram orientações técnicas quanto à utilização dos equipamentos de proteção. Esse argumento também é utilizado por alguns entrevistados do bairro Planalto, o que contraria o posicionamento de Arruda (2011), que destaca: 
É necessário garantir que a AUP contribua para uma melhor segurança alimentar urbana, sendo necessário um suporte em termos orientação técnica e treinamento sobre boas práticas de produção, e educação para agricultores e consumidores. Além disso, os potenciais riscos à saúde, causados pelo uso de esgotos e agroquímicos, manuseio inadequado de alimentos, poluição urbana e a criação de animais próxima a pessoas, juntamente com a falta de saneamento (ARRUDA, 2011, p. 18).

Os agricultores do bairro Vila Nova são os que têm maior indicativo de treinamento e assistência técnica. Utilizam agroquímicos somente quando necessário, de acordo com as instruções técnicas que a maioria recebeu.

O Quadro 11 mostra a utilização de agroquímicos: 8\% não utilizam nenhum produto; $67 \%$ usam adubação e cultura armadilha; e $25 \%$ utilizam pulverização ou herbicida.

Quadro 11 - Utilização de agroquímicos no bairro Vila Nova

\begin{tabular}{|c|c|c|c|c|c|}
\hline Agricultor & $\begin{array}{l}\text { Há utilização de } \\
\text { agroquímicos? }\end{array}$ & $\begin{array}{l}\text { Como ocorre o } \\
\text { controle de pragas e } \\
\text { plantas invasoras? }\end{array}$ & $\begin{array}{l}\text { Recomendação } \\
\text { feita por } \\
\text { técnico? }\end{array}$ & $\begin{array}{l}\text { Utiliza } \\
\text { equipamentos de } \\
\text { proteção? }\end{array}$ & $\begin{array}{l}\text { Recebeu alguma } \\
\text { orientação com } \\
\text { relação aos } \\
\text { equipamentos de } \\
\text { proteção? } \\
\end{array}$ \\
\hline AUV1 & Sim & Herbicida & Sim & Sim & Sim \\
\hline AUV2 & Sim & $\begin{array}{l}\text { Adubação e cultura } \\
\text { armadilha }\end{array}$ & $\operatorname{sim}$ & Sim & Sim \\
\hline $\mathrm{AUV}_{3}$ & $\operatorname{Sim}$ & $\begin{array}{l}\text { Adubação e cultura } \\
\text { armadilha }\end{array}$ & Sim & Sim & $\operatorname{Sim}$ \\
\hline $\mathrm{AUV}_{4}$ & Sim & Não faço & Sim & Sim & Não \\
\hline AUV 5 & $\mathrm{Sim}$ & Pulverização & Sim & Sim & $\operatorname{Sim}$ \\
\hline AUV6 & $\mathrm{Sim}$ & $\begin{array}{l}\text { Adubação e cultura } \\
\text { armadilha }\end{array}$ & Sim & Sim & Sim \\
\hline AUV7 & Não & $\begin{array}{l}\text { Adubação e cultura } \\
\text { armadilha }\end{array}$ & Sim & Sim & Sim \\
\hline AUV8 & $\operatorname{Sim}$ & $\begin{array}{l}\text { Adubação e cultura } \\
\text { armadilha }\end{array}$ & Sim & Sim & $\operatorname{Sim}$ \\
\hline AUV9 & Sim & $\begin{array}{l}\text { Adubação e cultura } \\
\text { armadilha }\end{array}$ & $\operatorname{Sim}$ & Sim & Sim \\
\hline AUV10 & Sim & $\begin{array}{l}\text { Adubação e cultura } \\
\text { armadilha }\end{array}$ & Sim & Sim & Sim \\
\hline AUV11 & Sim & $\begin{array}{l}\text { Adubação e cultura } \\
\text { armadilha }\end{array}$ & Sim & Sim & Sim \\
\hline AUV12 & Sim & Pulverização & $\operatorname{sim}$ & Sim & $\operatorname{Sim}$ \\
\hline
\end{tabular}

Fonte: elaborado pelos autores

De acordo com AUV7, a maioria dos agricultores sempre optam pelo processo mais natural, por esse motivo é que grande parte do grupo tem o cuidado de utilizar como controle de pragas o processo de adubação, que consiste em fornecer nutrientes necessários ao solo para que a planta fique mais resistente ao ataque de pragas. 
Outro método bastante utilizado é a cultura armadilha, que consiste em plantar espécies susceptíveis a pragas ao redor da área plantada e assim atrair os insetos para ela.

Conforme Arruda (2011):

Para a agricultura sustentável as pragas e doenças são entendidas como um problema ocasionado pelo manejo inadequado do sistema de produção. Os métodos alternativos de controle buscam minimizar os problemas com pragas e doenças por meio da recomposição ou preservação do equilíbrio ecológico (ARRUDA, 2011, p. 94).

Em relação ao uso de proteção, todos os produtores, com exceção do AV4, receberam treinamento que orienta a utilização de roupas apropriadas, botas, chapéus, máscaras e protetor solar.

Quanto à recomendação de técnicos especializados, tanto no auxílio ao controle de pragas como em matéria de proteção, a maioria aponta órgãos como Sebrae e Senar, com exceção do agricultor AUV7 que tem formação na área e orienta seus funcionários e amigos que precisam de algum auxílio.

Conforme dados do Quadro 12, dos produtores do bairro Planalto 34\% não utilizam nenhum produto para o controle de pragas e doenças; $33 \%$ usam barragem e $33 \%$ uma solução de ninho.

Os resultados que constam no Quadro 12 apontam que não existem muitos problemas com relação a pragas, pois na região onde está localizada a plantação há muitas plantas que colaboram afastando-as.

Agricultores do bairro Planalto utilizam alguns produtos naturais para 0 controle de pragas, como os do bairro Bacuri que usam uma solução de ninho e um produto natural preparado com álcool, fumo e sabão de coco. Consideram o produto eficaz e indicam a orientação dos técnicos do Sebrae.

Produto natural para o controle de praga é citado por Arruda (2011) em pesquisa realizada na Região Metropolitana do Rio de Janeiro. Os agricultores urbanos dessa região também utilizam produto natural semelhante, elaborado com álcool, sabão de coco e fumo. 
Quadro 12 - Utilização de agroquímicos no bairro Planalto

\begin{tabular}{|c|c|c|c|c|c|}
\hline Agricultor & $\begin{array}{c}\text { Há utilização } \\
\text { de } \\
\text { agroquímicos? }\end{array}$ & $\begin{array}{l}\text { Como ocorre o } \\
\text { controle de } \\
\text { pragas e plantas } \\
\text { invasoras? }\end{array}$ & $\begin{array}{l}\text { Recomendação } \\
\text { feita por técnico? }\end{array}$ & $\begin{array}{c}\text { Utiliza } \\
\text { equipamentos de } \\
\text { proteção? }\end{array}$ & $\begin{array}{c}\text { Recebeu alguma } \\
\text { orientação com relação } \\
\text { aos equipamentos de } \\
\text { proteção? }\end{array}$ \\
\hline AUP1 & Não & Não uso & Não & $\operatorname{Sim}$ & Não \\
\hline AUP2 & Não & Não uso & Não & Sim & Não \\
\hline$A \cup P_{3}$ & Não & Não uso & Não & Sim & Não \\
\hline AUP4 & Não & Solução de ninho & Sim & $\operatorname{Sim}$ & Sebrae \\
\hline AUP5 & Sim & Barragem & Não & Sim & Não \\
\hline AUP6 & $\operatorname{Sim}$ & Barragem & Não & $\operatorname{Sim}$ & Sebrae \\
\hline AUP7 & Não & $\begin{array}{l}\text { Álcool, fumo e } \\
\text { sabão de coco }\end{array}$ & Não & Sim & Não \\
\hline AUP8 & Não & Solução de ninho & Não & Sim & Sebrae \\
\hline AUP9 & Não & Solução de ninho & $\operatorname{Sim}$ & Sim & Sebrae \\
\hline AUP10 & Não & $\begin{array}{l}\text { Álcool, fumo e } \\
\text { sabão de coco }\end{array}$ & Não & $\operatorname{Sim}$ & Sebrae \\
\hline AUP11 & Sim & Barragem & Não & $\operatorname{Sim}$ & Não \\
\hline AUP12 & $\operatorname{Sim}$ & Barragem & Não & $\operatorname{Sim}$ & Não \\
\hline
\end{tabular}

Fonte: elaborado pelos autores

Quanto à proteção durante a execução das atividades, $100 \%$ contam com equipamentos de proteção individual; $58 \%$ não receberam nenhuma orientação de como usá-los e $42 \%$ receberam orientação do Sebrae.

Todos os agricultores utilizam, botas, chapéu e blusa de manga longa, como os do bairro Bacuri, justificando que uma simples camisa ou bota é considerado material de proteção, seja para combater o Sol ou proteger os pés. Não necessariamente protege de agroquímicos.

\section{Considerações Finais}

Esta pesquisa foi elaborada a partir do diagnóstico da agricultura urbana no município de Imperatriz (MA) e suas atribuições ligadas aos aspectos social e econômico e às práticas agrícolas sustentáveis.

Vale destacar que no primeiro momento da pesquisa, na fase exploratória, houve dificuldade para obter informações, pois não existem dados de órgãos públicos do município referentes à identificação dos bairros que contam com a agricultura urbana, além do não reconhecimento desse tipo de agricultura como urbana e sim como uma atividade rural, mesmo acontecendo no meio urbano.

A única referência encontrada foi do bairro Vila Nova, em virtude de o projeto ser executado pela Infraero, mas sem nenhum registro oficial pelos órgãos competentes da cidade. A identificação dos bairros foi realizada a partir de informações das comunidades e não em registros de produtores urbanos feitos por órgãos administrativos do município.

Outra limitação encontrada no início da pesquisa refere-se aos agricultores urbanos, já que muitos que se apresentavam para a pesquisa tinham o propósito de oferecer dados para órgãos administrativos do município. 
Posteriormente, esses dados iriam beneficiar a administração municipal como iniciativa que muitas vezes nem existiu e nem iriam contribuir para auxiliar o público envolvido na produção e reconhecimento do trabalho. Houve, então, nesse primeiro contato, dificuldade com relação à confiança, no sentido de participar da pesquisa e dar as informações nas entrevistas.

Os resultados obtidos permitem definir e caracterizar a agricultura urbana no município de Imperatriz (MA), identificando os produtores urbanos e descrever o tipo de contribuição socioeconômica e ambiental que a agricultura urbana proporciona às famílias que a praticam.

No que tange à contribuição socioeconômica que a agricultura urbana proporciona às famílias que a praticam, os agricultores destacam a sobrevivência como fonte de renda e emprego, como também contribuição na alimentação, lazer, auxílio contra o estresse e o fato de poder continuar exercendo a função que sempre atuaram em suas vidas.

Destaca-se, também, que alguns iniciaram na agricultura urbana como uma necessidade por conta do desemprego, e que encontraram em amigos uma fonte de aprendizagem para a subsistência da família.

Nesse aspecto é possível determinar que a agricultura urbana se apresentou como uma atividade com grande potencial de melhoria de qualidade de vida dos entrevistados envolvidos, mas que enfrentam dificuldades quanto ao apoio técnico, político e à participação em programas, além da falta de comunicação e orientação para aquisição de crédito para melhor atuarem em sua profissão e adquirirem insumos e produção.

Referente à identificação das práticas agrícolas sustentáveis envolvidas na agricultura urbana no município, primeiramente é visível que o planejamento integrado ao design urbano não existe em relação à agricultura urbana. Pode haver agora uma contribuição para o conforto e saúde dos cidadãos com a utilização eficaz dos espaços urbanos com áreas verdes em espaços antes abandonados dentro da cidade.

Em relação às práticas agrícolas no meio urbano, pode contribuir para a melhoraria do clima da cidade, reduzindo a temperatura, a poluição e terrenos baldios, como foram identificadas as áreas onde se desenvolvem as práticas agrícolas no município de Imperatriz.

Com os argumentos abordados nesse primeiro momento é possível diagnosticar a atividade agrícola urbana como uma atuação fundamental, que deve ser incluída no processo de planejamento urbano das cidades, uma vez que constitui uma realidade cultural que os centros urbanos absorveram e de uma prática multifuncional que promove o processo econômico, social e ecológica.

Conforme apontam os resultados, os agricultores citados na pesquisa são responsáveis por grande parte do abastecimento da maior rede de supermercados do estado do Maranhão e ainda atendem às regiões circunvizinhas, outros municípios e até outros estados.

Atendem, também, as concentrações locais de cada bairro: pequenos comércios, feiras e mercados, movimentando a economia local e influenciando no desenvolvimento de atividades na produção de produtos orgânicos, processamento, prestação de serviço e comercialização. 
Os insumos produzidos no município reduzem os custos dos sistemas de distribuição, assim como o transporte dos insumos de outras áreas, reduzindo os preços para a comunidade, já que os insumos são produzidos no próprio município e não importados de outras regiões, como antes da expansão da agricultura urbana em Imperatriz.

Essa é uma das características identificadas na agricultura urbana estudada, que modificou os aspectos socais e econômicos da cidade. Há vantagens e oportunidades e a agricultura urbana hoje é responsável por atender diferentes realidades e níveis da população local e regional.

Apesar de a maioria dos agricultores urbanos utilizar insumos típicos da agricultura orgânica, foi possível diagnosticar que grande parte desses produtores não participaram de cursos para utilização de técnicas mais apuradas, portanto, ainda utilizam as de produção e as de controle de pragas da agricultura rural.

Constata-se a necessidade da ampliação do conhecimento desses agricultores diante das mudanças direcionadas ao manejo da matéria orgânica e fertilidade do solo e controle de pragas e doenças.

Com esses resultados evidencia-se agricultura urbana, assim como a contribuição socioeconômica proporcionada aos agricultores e à comunidade, além das práticas agrícolas sustentáveis.

Por fim, no andamento da pesquisa foi possível constatar a necessidade de projetos que possam ampliar trabalhos que venham a contribuir com estudos nas respectivas comunidades envolvidas na pesquisa, que possam contribuir de forma positiva para um maior crescimento da agricultura urbana e maior reconhecimento, como manejo da matéria orgânica, fertilidade do solo, controle de pragas e manejo de resíduos em áreas urbanas.

São necessárias também a disponibilidade de informações, seja por órgão administrativo estadual ou municipal no que tange a políticas de apoio que possam contribuir no desenvolvimento desses agricultores, além de criar um banco de dados das iniciativas relacionadas à agricultura urbana e registro de dados dos produtores urbanos, algo que não existe conforme verificado no início da pesquisa.

O papel da agricultura urbana é visível quando se trata de uma atividade que muitas famílias identificam com uma execução de subsistência para aqueles que produzem e conseguem vender seus produtos graças a um diferencial no sistema produtivo, que é o orgânico.

Há necessidade de registro de dados que possa repassar informações de indicadores socioeconômicos e ambientais das atividades direcionadas à agricultura urbana proporcionadas ao município ou Estado, como também sistematizar dados e estratégias de produção que possam dar a esses produtores uma redução de custos e evitar possíveis riscos ao meio ambiente ou até mesmo à saúde.

É necessário, então, um planejamento para visualizar a agricultura urbana de acordo com a expansão e evolução da cidade, contribuindo com formas de cultivo mais desenvolvidas e mais tecnológicas.

\section{REFERÊNCIAS}

APPOLINÁRIO, F. Metodologia científica: filosofia prática da pesquisa. São Paulo: Thomson Learning, 2006. 
AQUINO, A. M.; ASSIS, R. L. Agricultura orgânica em áreas urbanas e periurbanas com base na agroecologia. In: Ambiente \& Sociedade. Campinas, v. x, n. 1. 2007. pp. 137-150.

AQUINO, A. M.; MONTEIRO, D. Agricultura urbana. In: AQUINO, A. M.; ASSIS, R. L. (Org.). Agroecologia: princípios e técnicas para uma agricultura orgânica sustentável. Brasília: Embrapa Informação Tecnológica, 2005.

ARRUDA, J. Agricultura urbana na região metropolitana do Rio de Janeiro: sustentabilidade e repercussões na reprodução das famílias. 2011. 197f. Tese (Doutorado em Ciências). UFRRJ, Seropédica. Disponível em: <http://r1.ufrrj.br/cpda/dissertacoes-e-teses/teses-doutorado 2011-2/>. Acesso em: 20 dez. 2016.

BOUKHARAEVA, M. L.; CHIANCA, G.; MARLOIE, M. A.; MACHADO, T. M.; MACHADO, T. T. C. Agricultura Urbana como um componente de desenvolvimento humano sustentável: Brasil, França e Rússia. In: Cadernos de Ciência e Tecnologia. Brasília, v. 22. 2005.

CAMPILAN, D.; DRECHSEL, P.; JÖCKER, D. Métodos de monitoreo y evaluación y su adaptación a la agricultura urbana y peri-urbana. Disponível em:

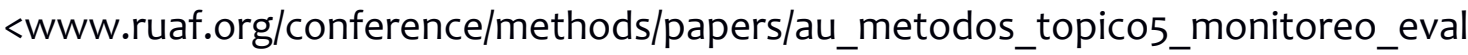
uacion_es.doc> Acesso em: 15 fev. 2017.

FAO. ORGANIZAÇÃO DAS NAÇÕES UNIDAS PARA ALIMENTAÇÃO E AGRICULTURA. A agricultura urbana e periurbana na agenda política. In: Relatório da Conferência eletrônica conjunta FAO/ETC. Roma, 2000.

FAO. ORGANIZAÇÃO DAS NAÇÕES UNIDAS PARA ALIMENTAÇÃO E AGRICULTURA. World reference base for soil resources. FAO/ISSS/ISRIC. (FAO. World Soil Resources Reports 84). Roma, 1999.

INFRAERO. EMPRESA BRASILEIRA DE INFRAESTRUTURA AEROPORTUÁRIA. Projetos Sociais. Disponível em:

<http://www.infraero.gov.br/index.php/br/aeroportos/maranhão/>. 2011. Acesso em 15 de jan. 2018.

INTERNATIONAL FOOD POLICY RESEARCH INSTITUTE (IFPRI). Food consumption and nutrition: urban challenges to food and nutrition security. 1998. Disponível em:<http:// www.cgiar.org/ipri>. Acesso em: 26 ago. 2016.

MACHADO, A. T.; MACHADO, C. T. T. Agricultura urbana. (Embrapa Cerrados. Documentos, 48). Planaltina: Embrapa Cerrados, 2002.

MENDONÇA M; MONTEIRO D. M. Quintais na cidade: a experiência de moradores da periferia do Rio de Janeiro. In: Agriculturas, v. 1, nº 0, p. 29-31, set./2004. 
MENEZES, F; BURLANDY, L.; MALUF, R. S. A construção de uma política de segurança alimentar. In: Conferência Nacional de Segurança Alimentar e Nutricional, 2004, Documentos... Olinda: SESC São Paulo, 2004.

MINISTÉRIO DA AGRICULTURA, PECUÁRIA E ABASTECIMENT. MAPA. Produtos orgânicos: o olho do consumidor / Ministério da Agricultura, Pecuária e Abastecimento. Secretária de Desenvolvimento Agropecuário e Cooperativismo Brasilia: MAPA/ACS, 34p. 2010.

MOLDAKOV, O. Apoio à agricultura urbana precisa de mais integração em San Petersburgo. In: La Revista Agricultura Urbana. vol. 4. jul./2001. Disponível em: <http:/www.ipes.org/aguila>. Acesso em: 03 set. 2016.

MOUGEOT, L. J. A. Agricultura urbana: conceitos e definições. In: Revista de Agricultura Urbana, Ottawa, n. 1, dez. 2005. Disponível em: <http://www.ruaf.org/sites/default/files/AU1conceito.pdf>. Acesso em: 26 agos. 2016.

MOUGEOT, L. J. A. Urban agriculture: definition, presence, potentials and risks. In: BAKKER, M., DUBBELING, M., SABEL-KOSCHELLA, U., ZEEUW, H. (Eds.). Growing Cities Growing Food: Urban Agriculture on the Policy Agenda. DSE, Feldafing, Germany. ISBN 3-934068-25-1, 2000.

. Growing better cities: urban agriculture for sustainable development.

Ottava: IDRC, 2006.

NOLASCO, C. L. A agricultura urbana no desenvolvimento sustentável dos municípios. 2009. 166f. Trabalho de Conclusão de Curso (Especialização em gestão ambiental) - Curso em Gestão Ambiental em Municípios, Universidade Federal de Juiz de Fora, 2009.

NOLASCO, C. L. Demanda e abastecimento de hortaliças na microrregião de São José dos Campos, Brasil: Implicações para a segurança alimentar e desenvolvimento sustentável no contexto das mudanças globais. 2016. 254f. Tese (Doutorado em Ciência do Sistema Terrestre). Instituto Nacional de Pesquisas Espaciais, São José dos Campos, 2016.

NUGENT, R.; EGAL, F. Agricultura urbana e periurbana: segurança alimentar e nutrição. Texto inicial para discussão na conferência eletrônica, promovida pela FAO, ETC, RUAF, 2000.

SMIT, J. Urban Agriculture information: the urban agricultural network (TUAN). Washington, 1994.

SOARES, A. C. O. A multifuncionalidade da agricultura familiar. In: Revista Proposta. Rio de Janeiro: Fase. n. 87, 2001. 
SODERBERG, A. M. Sensegiving and sensemaking in na integration process: A narrative approach to the study of na international acquisition In: CZARNIAWSKA, B; GAGLIARDI. Narratives we organize by. Amsterdam; Philadelphia, PA: John Benjamins, 2008.

Edson Aparecida Araujo Querido Oliveira. Economista, Mestre em Economia pela Pontifícia Universidade Católica de São Paulo (PUCSP)- Doutor em Engenharia Aeronáutica e Mecânica pelo Instituto Tecnológico de Aeronáutica (ITA). Pós-Doutor em Gestão da Inovação Tecnológica pelo Instituto Tecnológico de Aeronáutica (ITA). Coordenador Geral e Professor do |Programa de Pósgraduação em Gestão e Desenvolvimento Regional da Universidade de Taubaté (UNITAU).edsonaaqo@gmail.com

Luciana Learte Moura Nunes. Administradora. Mestre em Gestão e Desenvolvimento Regional (UNITAU). Professora do Instituto Federal do Maranhão.luciananunues@ifma.edu.br

Marcela Barbosa de Moraes. Economista. Mestre em Gestão e Desenvolvimento Regional (UNITAU). Doutora em Administração (UNINOVE). Professora do |Programa de Pós-graduação em Gestão e Desenvolvimento Regional da Universidade de Taubaté (UNITAU).marcelabmoraes@gmail.com 